\title{
Evaluation of GlobCurrent surface ocean current products: A case study in Australia
}

\author{
Cancet Mathilde ${ }^{1,{ }^{*}}$, Griffin David ${ }^{2}$, Cahill Madeleine ${ }^{2}$, Chapron Bertrand ${ }^{3}$, Johannessen Johnny ${ }^{4}$, \\ Donlon Craig ${ }^{5}$
}

${ }^{1}$ NOVELTIS, France

${ }^{2}$ CSIRO, Australia

${ }^{3}$ IFREMER, France

${ }^{4}$ NERSC, Norway

${ }^{5}$ ESA/ESTEC, Netherlands

* Corresponding author : Mathilde Cancet, email address : mathilde.cancet@noveltis.fr

\begin{abstract}
:
Australia's marginal seas include a wide range of ocean current regimes ranging from tide-dominated in the North-West where the continental shelf is wide, to boundary current- and eddy-dominated in the South-East, where the shelf is narrow. Here, we take the opportunity to test the GlobCurrent surface ocean current products against in-situ observations in these two contrasting regimes. Observations by Acoustic Doppler Current Profiler (ADCP) instruments of Australia's Integrated Marine Observing System (IMOS) and drifting buoys of the Global Drifting Programme (GDP) are used.
\end{abstract}

The monthly-timescale variability of the GlobCurrent alongshore current component is in moderately good agreement with the observations on the continental shelf in the South-East but neither the shorter period variability nor the long-term mean are representative of the ADCP observations. While the observed tidal currents are negligibly small, the wind-driven signals are not. But these are evidently too transient to be adequately sampled by altimetry. The inclusion of an Ekman component does not represent these signals because the interaction of the Ekman transport with the coastal boundary condition is not included. Similarly, the error of the time-mean velocity, which is the dominant error, is because that product is not designed to represent the highly anisotropic nature of the sea level gradients over the continental shelf nor the constraints on the flow field that are imposed by the topography. We thus conclude that the GlobCurrent product needs improvements before it can be described as very suitable for applications on this, and probably other, narrow continental shelf. Off the continental shelf, in contrast, the GlobCurrent products compare quite well with the trajectories of drifting buoys, confirming that the products are quite suitable for blue-water applications.

In contrast to the South-East, the tides are very strong in the North-West region of Australia. The subtidal variability is weak, in both relative and absolute senses. Consequently, the removal of the tidal signal from the sea level observations needs to be very complete for the residual error to be smaller than the true sub-tidal signal. Transient wind forced signals are also occasionally large so this step of the de-aliasing also needs to be very accurate. Unfortunately, it appears that more work is required before accurate estimates of sub-tidal variability are available from GlobCurrent: the magnitude of the GlobCurrent estimates of sub-tidal current variability far exceed the magnitude of, and are uncorrelated 
with, the detided ADCP data.

\section{Highlights}

- We compare the GlobCurrent ocean surface currents with in situ data in Australia. The structures (eddies, currents) larger than $100 \mathrm{~km}$ are rather well described. On wide shelves, tidal currents estimates should be added to GlobCurrent products.

Keywords : Surface ocean currents, GlobCurrent assessment, East Australian Current, Tidal currents, In situ measurements 


\section{Introduction}

There is currently no instrument onboard satellites that can directly provide the total surface ocean currents worldwide. Some satellite missions with this objective are under study (SEASTAR ex-WAVEMILL (Martin and Gommenginger, 2017), SKIM (Ardhuin et al, 2017)) but, today, the estimation of the total surface ocean currents from remote sensing observations can only be made through the combination of observations provided by various instruments and after application of approximate models. The geostrophic currents are derived from the satellite altimetry observations and the Ekman drift is derived from the wind observations. This method, classically used by several ocean current products providers (AVISO (Le Traon and Dibarboure, 2002), OSCAR (Bonjean and Lagerloef, 2002), GEKCO (Sudre et al, 2013), GlobCurrent (Rio et al, 2014; Rio, 2015)), is based on the assumption that the dominant signals in the surface ocean currents are the geostrophic component and the Ekman drift. This approximation is adequate in much of the open ocean (away from the equator), especially for time scales longer than the inertial period. On the continental shelves, other ocean dynamics processes such as the tidal currents can dominate the ocean circulation. Ignoring this contribution to the total surface ocean currents can lead to underestimating dramatically the currents in regions with large tidal amplitudes.

This paper presents an assessment of the GlobCurrent surface ocean currents products produced and distributed in the framework of a project funded by the European Space Agency (ESA). This assessment focuses on Australia, a region characterized by a variety of ocean dynamics processes including large geostrophic structures such as the East Australian Current (EAC) and wide shelves where the tidal currents are predominant, in particular on the northwest coast.

A set of Acoustic Doppler Current Profiler (ADCP) stations as well as drifting buoys are used to evaluate the physical content of the GlobCurrent products in the East Australian 
Current (EAC) region and to quantify the omission error made on the macro-tidal shelf of the Joseph Bonaparte Gulf.

\section{Data}

\subsection{GlobCurrent products}

The GlobCurrent surface ocean currents products (version 3.0) are provided on a 1/4 ${ }^{\circ}$ grid, over the 1993-2016 period. The geostrophic currents and the Ekman currents are provided separately, on daily and 3-hourly bases, respectively, and also combined in a "total surface currents" product, which is the sum of the two products and is distributed on a 3-hourly basis (Rio, 2015, http://www.globcurrent.org/).

The GlobCurrent geostrophic currents are derived from maps of satellite altimetry sea level anomalies (SLA), combined with the most recent Mean Dynamic Topography (MDT) field (CNES-CLS-2013 MDT, Rio et al, 2013), which provides an estimate of the time-mean geostrophic current. The spatiotemporal coverage of the satellite altimetry missions and the correlation scales used in the optimal interpolation process that generates the SLA and MDT maps imply that the intrinsic temporal resolution of the geostrophic currents products is about 10 days and the spatial resolution is in the order of 100-150 km (Ubelman et al, 2015).

The GlobCurrent Ekman currents products are based on the Ekman model of Rio et al (2014). The Ekman currents are provided at $15 \mathrm{~m}$ below the surface and at the surface $(0 \mathrm{~m})$, by estimating the Ekman model parameters using the velocities derived from the trajectories of the drifting buoys drogued at $15 \mathrm{~m}$ on the one hand and the velocities derived for the Argo float trajectories on the other hand (Rio et al, 2014). To tune the Ekman model parameters, the drifting buoys data are filtered using an inertial-period-to-20-days band-pass filter, which corresponds to the frequencies of maximum coherency between the wind stress and the Ekman currents (Rio et al, 2014). The Ekman model is then applied to the 3-hourly ECMWF wind 
stress fields ( $80 \mathrm{~km}$ of spatial resolution) to produce the GlobCurrent Ekman current products (Rio, 2015).

\subsection{In situ data}

For more than 10 years, Australia has been maintaining a network of about 50 ADCP instruments all around the country (Australian National Mooring Network facility), principally through the government-supported Integrated Marine Observing System (IMOS). Time series of ocean current velocities are available over periods of several years, at various depths in the water column and with temporal sampling of 5 to 15 minutes, depending on the stations. For details, see http://oceancurrent.imos.org.au/timeseries/.

For this study, we considered four ADCP stations along the New South Wales coast, where the East Australian Current flows: NRSNSI (North Stradbroke Island, off Brisbane), CH100 (Coffs Harbour), SYD100 and SYD140 (Sydney). ADCP velocities considered in this study were all chosen close to $15-\mathrm{m}$ depth, to avoid the zone of side-lobe interference between the surface and approximately $12 \%$ of the depth of the ADCP. The locations of these ADCP stations were checked in order to be sure that they were not mainly representative of some very local dynamics that would not be sampled in the grid of the GlobCurrent products.

Three other ADCP stations were considered on the macro-tidal shelf of the Joseph Bonaparte Gulf: the Margaret Harries Banks (ITFMHB) station, the Flat Top Banks (ITFFTB) station and the Joseph Bonaparte Gulf (ITFJBG) station. These three ADCP stations were specifically processed to extract the tidal current signal (see section 3.2). Given the temporal sampling of the ADCP observations, they contain much more high frequency signals than the GlobCurrent products and temporal filtering is needed to compare both datasets, as discussed in the next section.

Tens of drifters datasets are also available in the EAC region during the 1992-2015 period covered by the GlobCurrent products. The drifting buoys velocity observations come 
from the Global Drifter Program and were downloaded from the NOAA/AOML web-service. The eastward and northward ocean current components are provided at 6-hour temporal sampling for each buoy. In this paper, we focused on four of these drifting buoys, during the period 2009-2015. These four drifting buoys were chosen for their proximity to the New South Wales coast and the ADCP stations, and for the structures they described in the open ocean (EAC path and eddies of different sizes). The analysis was done during the "drogued period" of the drifters, i.e. before they lost their drogues, so that the velocities derived from the drifters trajectories are representative of the ocean currents at $15 \mathrm{~m}$ and can be compared with the GlobCurrent total ocean currents at 15-m depth (Lumpkin et al, 2013).

In general, the ADCP stations and the drifter buoys were chosen with the objective to ensure fair comparison. Indeed, some ADCP stations and drifters are so coastal that they fall out of the GlobCurrent $0.25^{\circ}$ grid. Some ADCP stations are also installed in sites with very specific dynamics that have almost no chance to be reproduced in the GlobCurrent products because of their coarser spatiotemporal resolution.

\section{Results}

\subsection{Assessment in a geostrophic structure: the East Australian Current}

\subsubsection{Coastal comparison with ADCP data}

The East Australian Current (EAC) is a complex western boundary system off the eastern coast of Australia, whose main pattern flows southward (Fig. 1). In terms of mean flow, the EAC is about $30-100 \mathrm{~km}$ wide and $200-500 \mathrm{~m}$ deep, with rather weak mean flow compared to the other western boundary currents (Suthers et al, 2011). However, the EAC is strongly dynamic and highly energetic, as it is dominated by highly variable mesoscale eddies, which results in the fact that its variability is often stronger than the mean flow (Bowen et al, 2005; 
Mata et al, 2006). The mean current flows along the steep continental shelf slope, close to the 200-m isobaths, as shown in Fig. 1 (100-m and 200-m isobaths are plotted in gray lines). The ADCP stations of NRSNSI (in $65 \mathrm{~m}$ of water) and $\mathrm{CH} 100$ are located close to the EAC mean path, in the region where the mean current is strongest. The two stations off Sydney (SYD100 and SYD140) are located in an area where the mean current is weaker and the variability of the current is larger, with the production of mesoscale eddies and the separation of the current in several branches (Ridgway and Hill, 2009). Such a configuration provides good conditions to assess the GlobCurrent ocean surface current products, both offshore and near the coast.

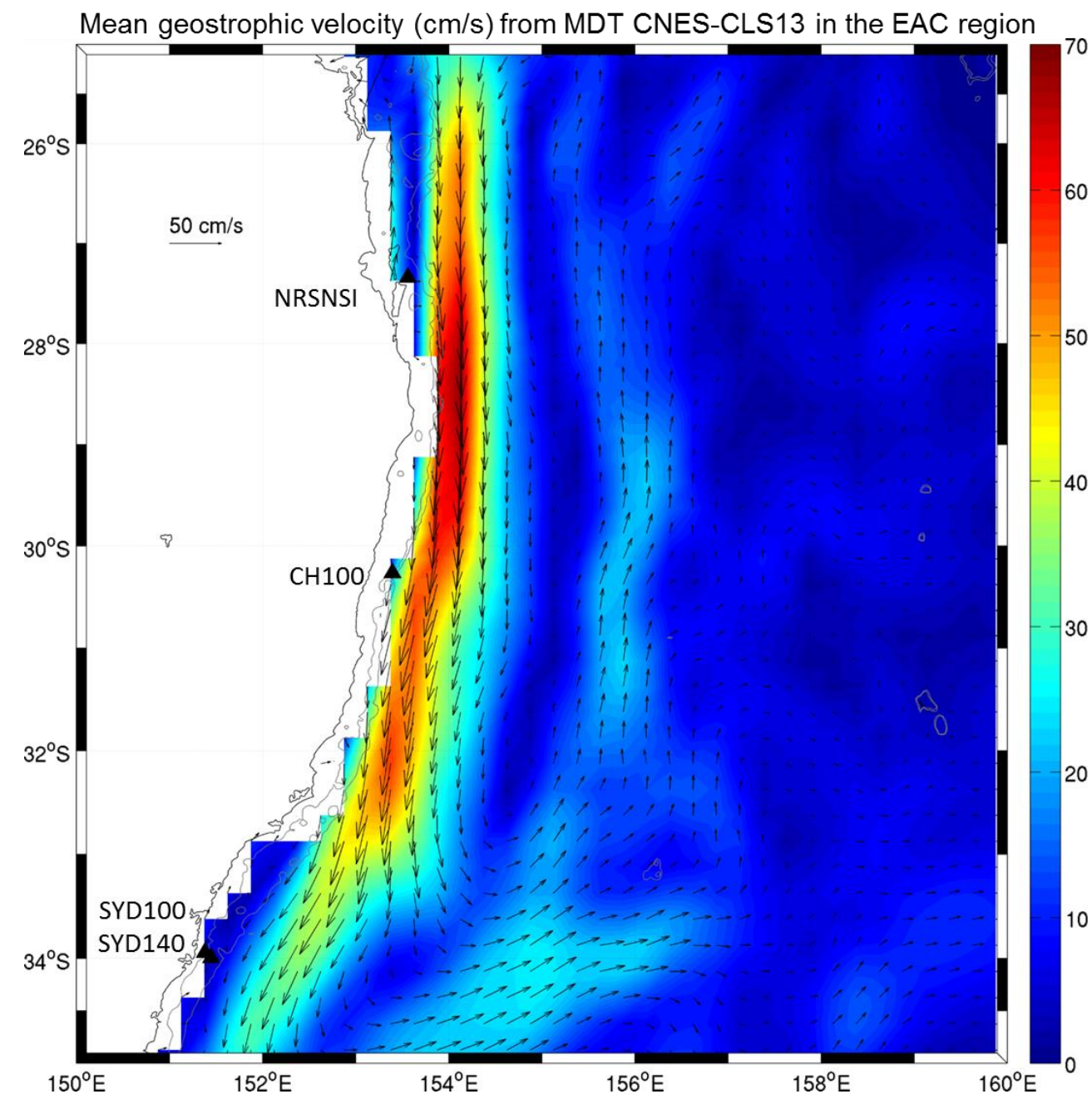

Figure 1 : Mean geostrophic velocities in $\mathrm{cm} / \mathrm{s}$ derived from the CNES-CLS131/4 ${ }^{\circ}$ Mean Dynamic Topography off New South Wales. The velocity magnitude is in color and the arrows give the direction and the amplitude of 
the current. The locations of the 4 ADCP stations are shown with black triangles. The light gray lines show the $100 \mathrm{~m}$ and $200 \mathrm{~m}$ isobaths.

The GlobCurrent ocean surface currents were extracted at the locations of the four ADCP stations for the geostrophic currents (daily) and the total currents at $15 \mathrm{~m}$ (3-hourly). The GlobCurrent total currents at $15 \mathrm{~m}$ are expected to show more consistent physical content with the ADCP observations at $15 \mathrm{~m}$, as they contain more ocean dynamics (geostrophic + Ekman currents) than the GlobCurrent geostrophic currents only. The spectral analysis of the GlobCurrent geostrophic currents, computed with the Fast Fourier Transform (FFT) method shows that there is very little signal at the location of the ADCP station at periods shorter than 25 to 30 days (Fig. 2 for the CH100 ADCP station in Coffs Harbour, similar results obtained for the three other stations, not shown here). In the meantime, the ADCP observations, with a temporal sampling of 5 to 15 minutes depending on the station, contain much high-frequency signal (in particular diurnal and semi-diurnal signals) as shown in Fig. 2. The spectral analysis of the GlobCurrent total currents at $15 \mathrm{~m}$ (not shown here) exhibits the same spectrum as the GlobCurrent geostrophic currents, with two additional diurnal and semi-diurnal energy peaks, due to the Ekman contribution. The comparison of the high frequency signals (under 48 hours) contained in the ADCP observations and in the GlobCurrent total surface currents at $15 \mathrm{~m}$ does not show any significant correlation at these ADCP stations. At Coffs Harbour (CH100), the amplitude of the high frequency signals in the ADCP currents is about two to three times the amplitude of the GlobCurrent total surface currents at $15 \mathrm{~m}$. Both datasets contain strong diurnal signals, generally in phase. However, it is difficult to draw any conclusions from the comparison at this temporal scale, as the ADCP observations contain more physical processes, such as the ocean tides (even if they are rather weak in this region) and Coastal Trapped Waves (Griffin and Middleton, 1991), while the GlobCurrent total currents products only contain the Ekman currents at this temporal scale. Given these considerations, the ADCP observations and 
the GlobCurrent products were filtered with a 30-day low-pass filter for the comparisons presented hereafter.
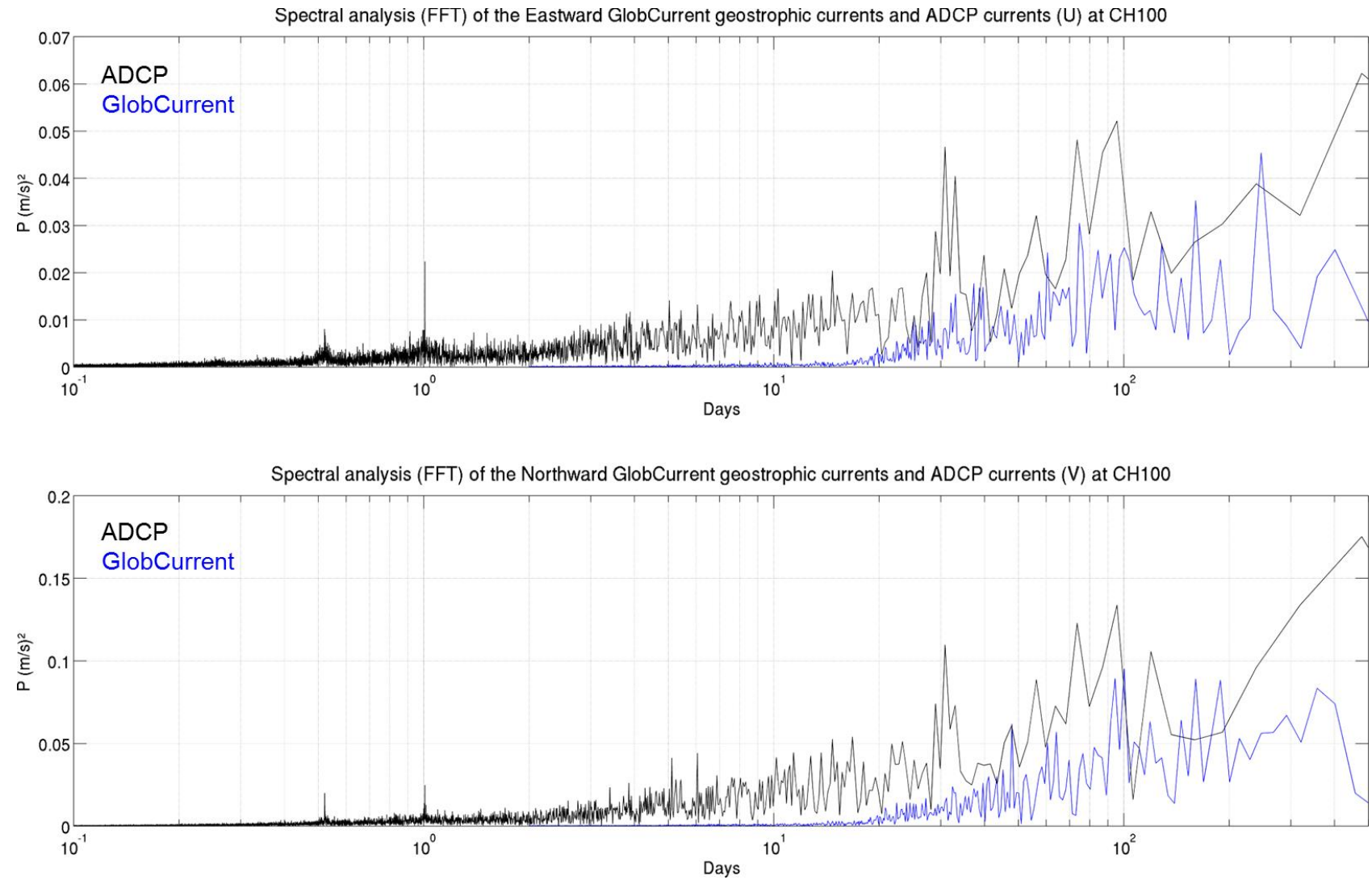

Figure 2: Spectral analysis of the CH1OO ADCP currents at 15 m (in black) and of the GlobCurrent geostrophic currents (in blue) extracted at the location of the CH1OO ADCP station in Coffs Harbour, in each current direction. The single-sided amplitude spectrum was computed using an FFT method.

The current roses (Fig. 3) plotted at each of the four ADCP stations show the number of occurrences in the observations for each angle of the ocean current direction $\left(0^{\circ}\right.$ is eastward, $90^{\circ}$ is northward). To build these plots, the ADCP observations were interpolated at the GlobCurrent geostrophic currents dates, over the common time period. In addition, Tab. 1 gives some statistics computed on the monthly means of the ADCP and GlobCurrent current estimates, for each of the four ADCP stations.

At the NRSNSI station, Fig. 3 shows that the GlobCurrent geostrophic current estimates are strongly variable, whereas the ADCP sees a very stable southeastward flow (the 
GlobCurrent total ocean surface currents at $15 \mathrm{~m}$ were not plotted at the NRSNSI station location because the station is off the GlobCurrent total current grid). The ADCP currents main direction is parallel to the orientation of the $100 \mathrm{~m}$ and $200 \mathrm{~m}$ isobaths, which means that the EAC probably follows the isobaths more closely than it is described in the CNES-CLS13 MDT product (see zoom in on the area on Fig. 4). In addition, the MDT shows a northward current all along the coast in this region, with amplitudes of about $30 \mathrm{~cm} / \mathrm{s}$, which is not realistic. In this coastal region, the satellite altimetry data used to build the MDT and the GlobCurrent products are certainly less accurate than in the open ocean, which leads to large errors in the time-mean and daily geostrophic current estimates. These poor results are confirmed by the statistics given in Tab. 1, where the correlations between the NRSNSI ADCP data and the GlobCurrent products are very low, and there is a noticeable mean bias of about $20 \mathrm{~cm} / \mathrm{s}$ on the norm of the currents between the two datasets.

At the two stations off Sydney (SYD100 and SYD140), the axis of variability of the ADCP and GlobCurrent currents are more consistent, but the directions of the mean differ (Fig. 3). In particular, at the SYD100 station, the ADCP currents are mainly oriented southwestward while the mean GlobCurrent velocity is northeastward. At the SYD140 station, the GlobCurrent currents are almost equally distributed between the southwestward and the northeastward directions, while the ADCP data clearly sees a southwestward flow. A zoom in on the mean geostrophic currents derived from the CNES-CLS13 MDT in the region off Sydney (Fig. 5) shows that, close to the SYD100 station, there is a mean northeastward current of about $15 \mathrm{~cm} / \mathrm{s}$ that flows along the coast in the CNES-CLS13 product, which is the basis of the GlobCurrent currents products. As for the SYD140 station, it appears to be located at a convergence between northeastward and southwestward flows in the MDT product, which can explain the large spatial variability of the GlobCurrent ocean current estimates at this point. Tab. 1 shows that the correlations in the separate current directions are higher at the SYD100 and SYD140 
stations ( 0.7 on the eastward component) than at the other stations. However, when considering the correlations on the current norms (including both directions at once), the statistics are very poor at the two stations off Sydney (less than 0.2), which is explained by the fact that the ADCP and GlobCurrent systems show the same large variations in the currents estimates but with very different amplitudes (see the time series of the monthly means of the currents for the SYD100 station in Fig. 6).

The Coffs Harbour station (CH100) is the closest to the main stable structure of the EAC and the comparison of the 30-day low-pass filtered observations shows the more consistent results. It is all the more true when considering monthly means of the current estimates, as shown in Fig. 7. Except for some periods when the ADCP and the GlobCurrent systems give opposite currents directions, a general agreement can be observed between all the datasets, with consistent amplitudes and correlations of 0.7 in the meridional direction, as shown in Tab. 1 . The seasonal variations of the EAC are also clearly visible, with intensification during the southern summer (December to February). In the zonal direction, the correlations are lower (about 0.50 ), because of the higher variability and lower amplitude of the currents in this direction, which is probably more difficult to capture with the current altimetry data processing strategies. The correlations on the current norms are also rather good (about 0.60, which is easily the highest score obtained among the four ADCP stations), and the RMS differences and biases computed on the current norms are low (a few $\mathrm{cm} / \mathrm{s}$ ), as summarized in Tab. 1.

This comparison with ADCP data shows that, in this region, the GlobCurrent products are poorly consistent with the coastal in situ observations, even at long temporal scales (more than 30 days), except in the case of the Coffs Harbour 100m ADCP station, which is located closest to the EAC path and observes some ocean dynamics that is largely influenced by the open ocean. 
Directions of the current at NRSNSI station 30-day filtered ADCP data

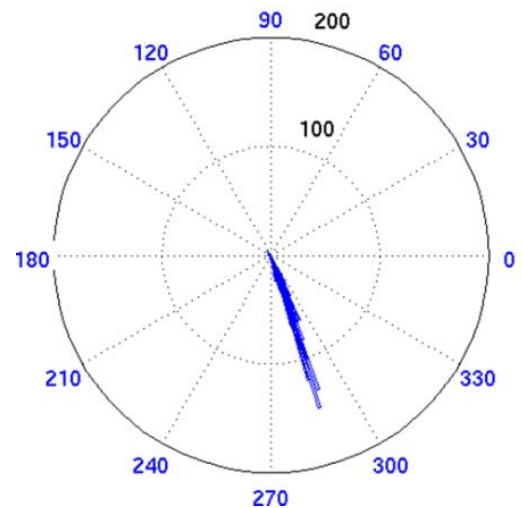

Directions of the current at $\mathrm{CH} 100$ station 30-day filtered ADCP data

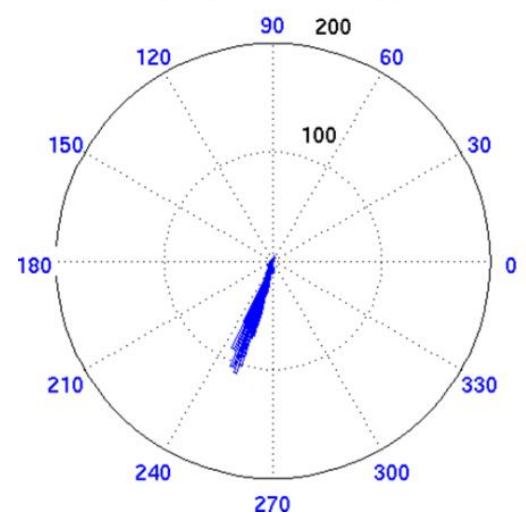

Directions of the current at SYD100 station 30-day filtered ADCP data

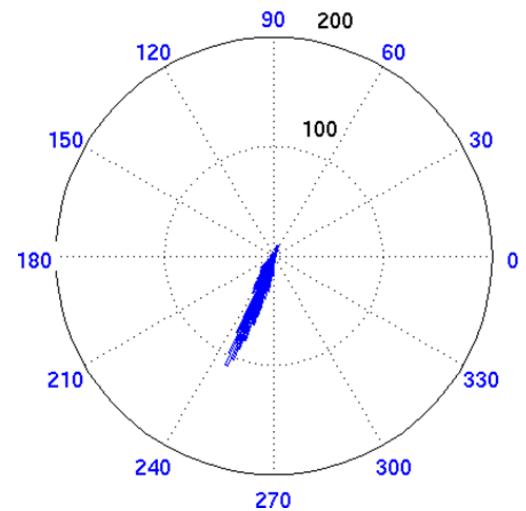

Directions of the current at NRSNSI station

30-day filtered GlobCurrent (geostrophic) data

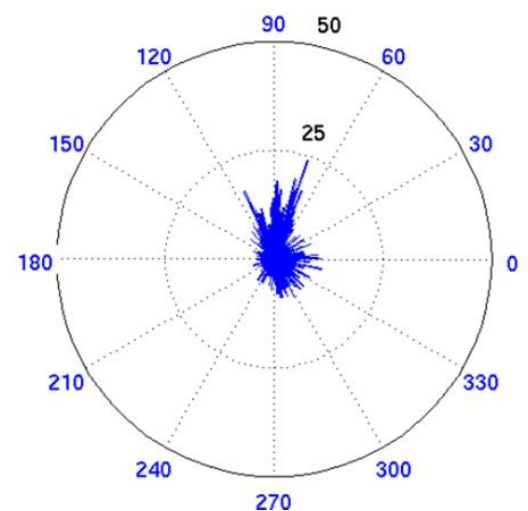

Directions of the current at $\mathrm{CH} 100$ station 30-day filtered GlobCurrent (geostrophic) data

Directions of the current at $\mathrm{CH} 100$ station
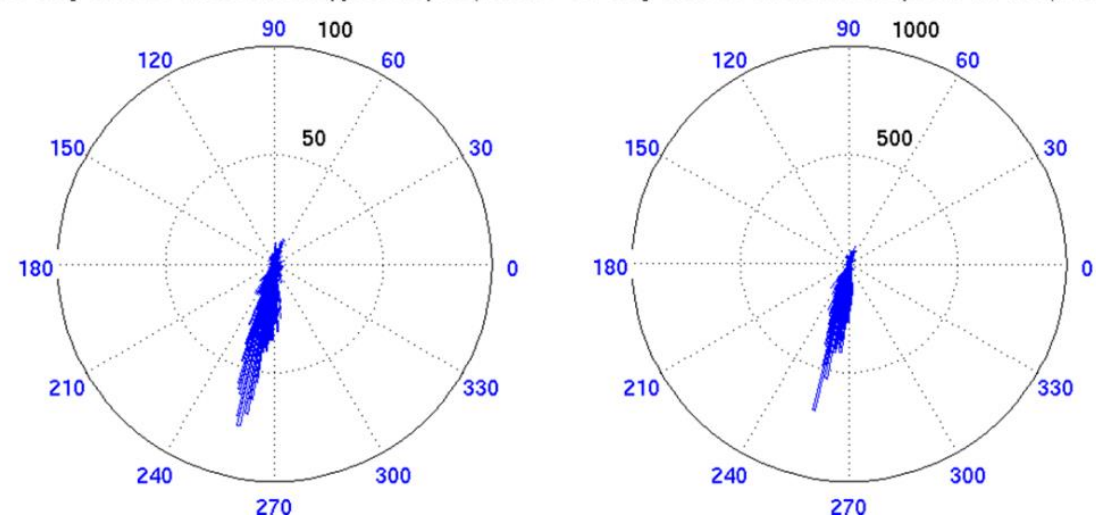

Directions of the current at SYD100 station

Directions of the current at SYD100 station 30-day filtered GlobCurrent (geostrophic) data 30-day filtered GlobCurrent (total at $15 \mathrm{~m}$ ) data

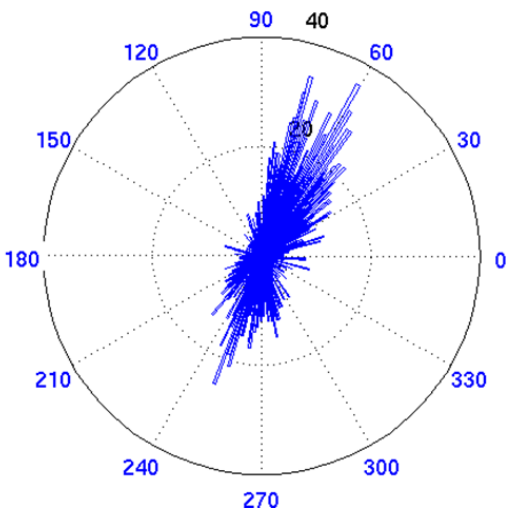


Directions of the current at SYD140 station 30-day filtered ADCP data

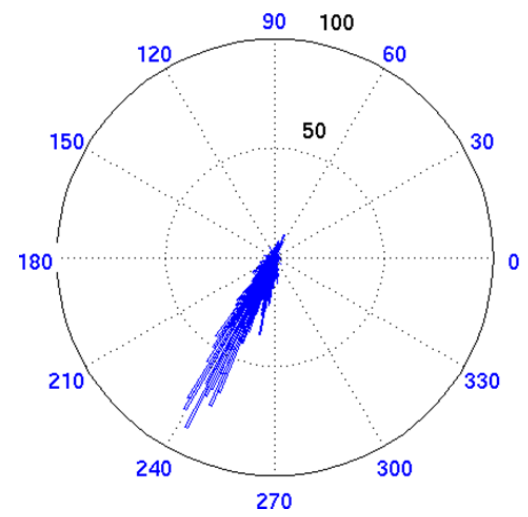

Directions of the current at SYD140 station 30-day filtered GlobCurrent (geostrophic) data

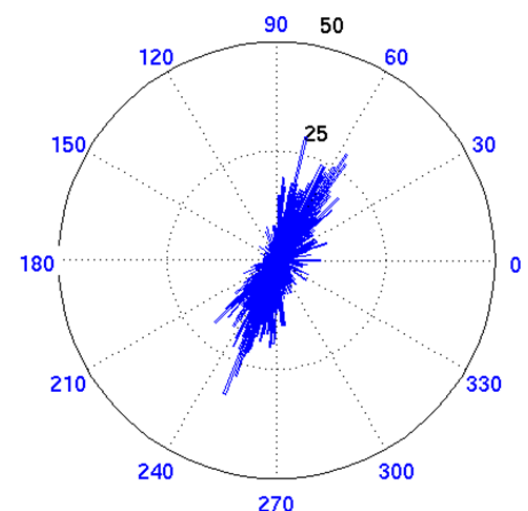

Directions of the current at SYD140 station 30-day filtered GlobCurrent (total at $15 \mathrm{~m}$ ) data

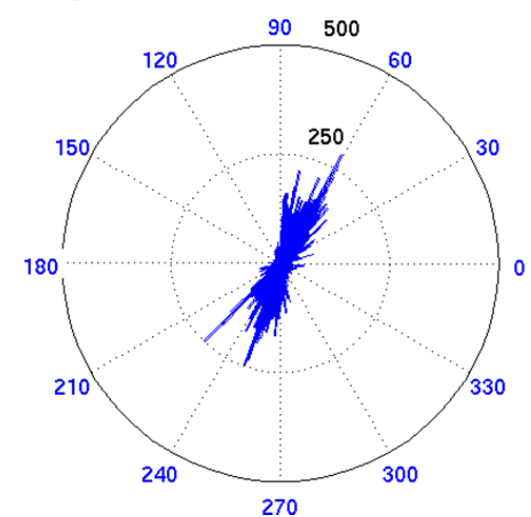

Figure 3 : Ocean current roses of the 30-day low-pass filtered ADCP observations and GlobCurrent products (geostrophic currents and total surface currents at $15 \mathrm{~m}$ ) for each of the four ADCP stations. The numbers in blue indicate the angle of the ocean current direction $\left(0^{\circ}\right.$ is eastward, $90^{\circ}$ is northward). The numbers in black and the concentric circles give the number of occurrences in the observations for each angle. The NSRNSI ADCP station is located out of the grid of the GlobCurrent total currents and no current rose was computed in this case.

Table 1: Statistics computed on the monthly means of the ADCP currents and the GlobCurrent geostrophic and total surface currents. The correlations are computed for each current direction separately (U-eastward, Vnorthward) and on the current norm. The RMS differences and the biases are computed on the current norm only, following the convention (GlobCurrent data-ADCP data). The NSRNSI ADCP station is located out of the grid of the GlobCurrent total currents and no statistics were computed in this case.

\begin{tabular}{|c|c|c|c|c|c|c|c|c|c|c|}
\hline \multirow{3}{*}{$\begin{array}{l}\text { ADCP } \\
\text { station }\end{array}$} & \multicolumn{5}{|c|}{ GlobCurrent geostrophic currents } & \multicolumn{5}{|c|}{ GlobCurrent total currents at $15 \mathrm{~m}$} \\
\hline & \multicolumn{3}{|c|}{ Correlation } & \multirow{2}{*}{$\begin{array}{c}\text { RMS diff. } \\
(\mathrm{m} / \mathrm{s})\end{array}$} & \multirow{2}{*}{$\begin{array}{l}\text { Bias } \\
(\mathrm{m} / \mathrm{s})\end{array}$} & \multicolumn{3}{|c|}{ Correlation } & \multirow{2}{*}{$\begin{array}{c}\text { RMS diff. } \\
(\mathrm{m} / \mathrm{s})\end{array}$} & \multirow{2}{*}{$\begin{array}{l}\text { Bias } \\
(\mathrm{m} / \mathrm{s})\end{array}$} \\
\hline & $\mathbf{U}$ & $\mathbf{V}$ & Norm & & & $\mathbf{U}$ & V & Norm & & \\
\hline NRSNSI & -0.02 & 0.24 & -0.02 & 0.17 & -0.19 & - & - & - & - & - \\
\hline CH100 & 0.49 & 0.68 & 0.59 & 0.14 & 0.06 & 0.52 & 0.69 & 0.60 & 0.15 & 0.07 \\
\hline SYD100 & 0.73 & 0.51 & -0.09 & 0.11 & 0.03 & 0.72 & 0.54 & -0.10 & 0.11 & 0.03 \\
\hline SYD140 & 0.68 & 0.65 & 0.18 & 0.11 & 0.04 & 0.70 & 0.67 & 0.19 & 0.11 & 0.04 \\
\hline
\end{tabular}




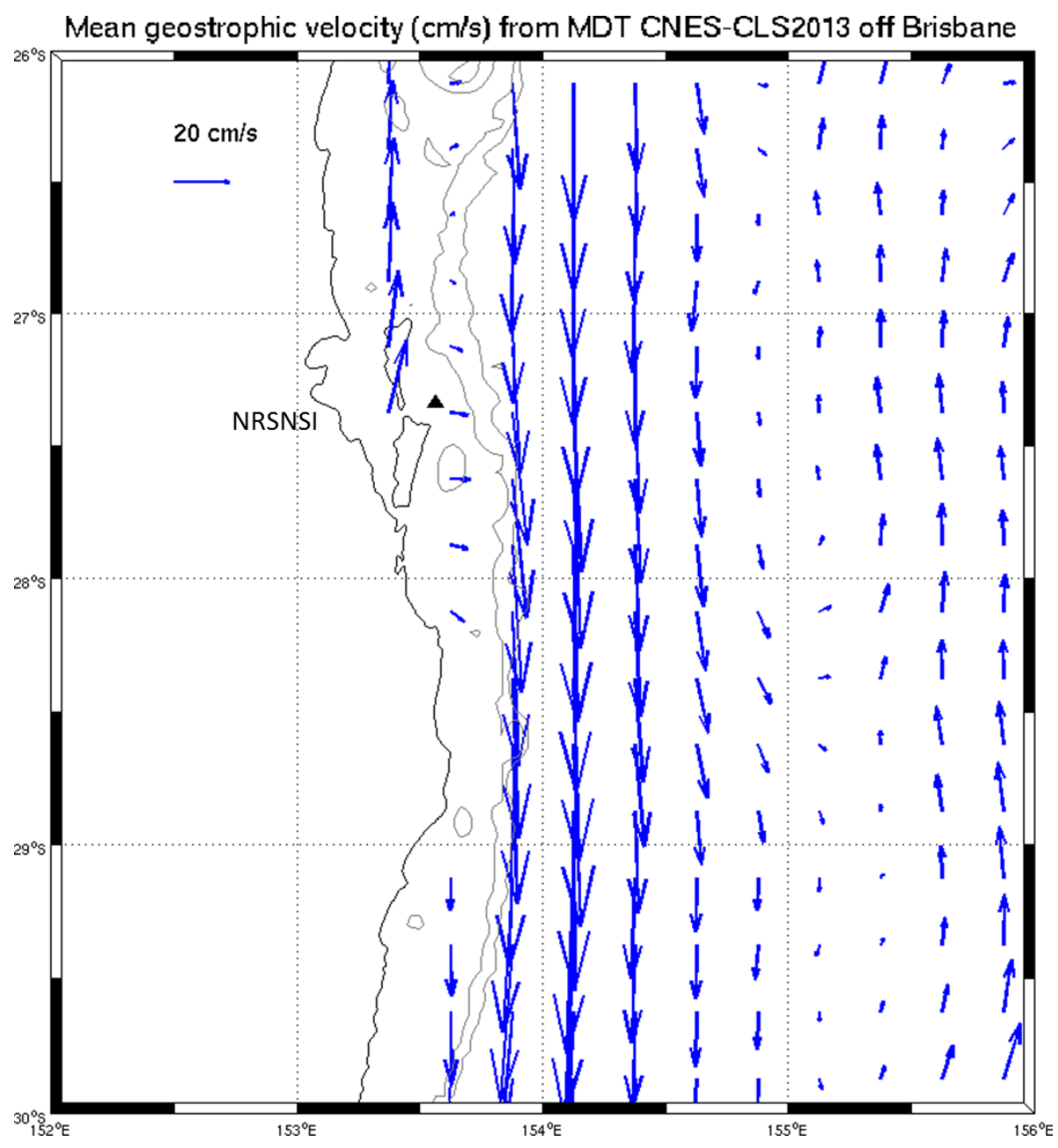

Figure 4 : Mean geostrophic velocities from the CNES-CLS13 1/4 ${ }^{\circ}$ Mean Dynamic Topography off Brisbane. The location of the NRSNSI ADCP station is shown with a black triangle. The light gray lines show the 100m and $200 \mathrm{~m}$ isobaths. 


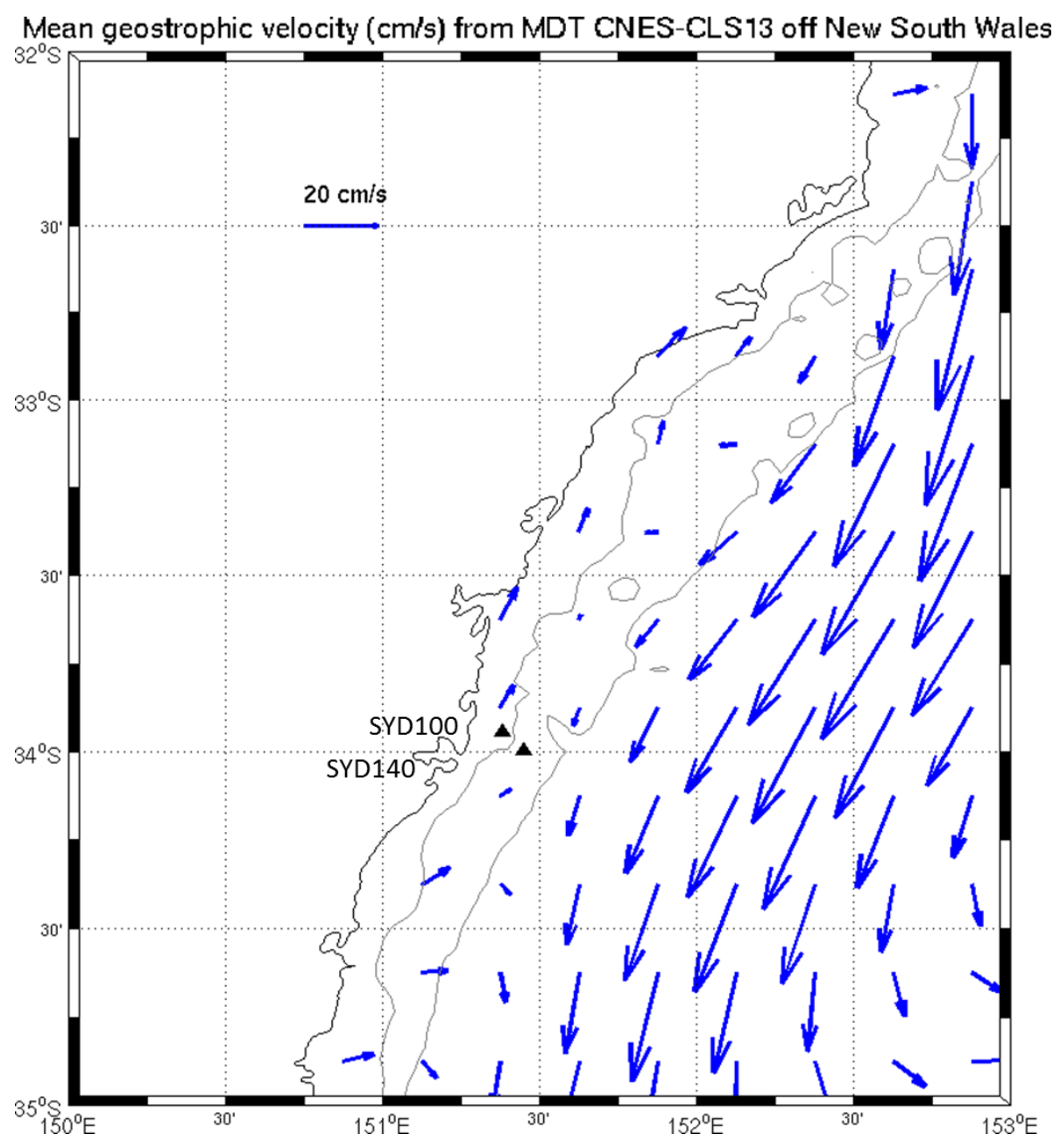

Figure 5 : Mean geostrophic velocities from the CNES-CLS13 1/4 Mean Dynamic Topography off New South Wales. The locations of the ADCP stations off Sydney are shown with black triangles. The light gray lines show the $100 \mathrm{~m}$ and $200 \mathrm{~m}$ isobaths. 

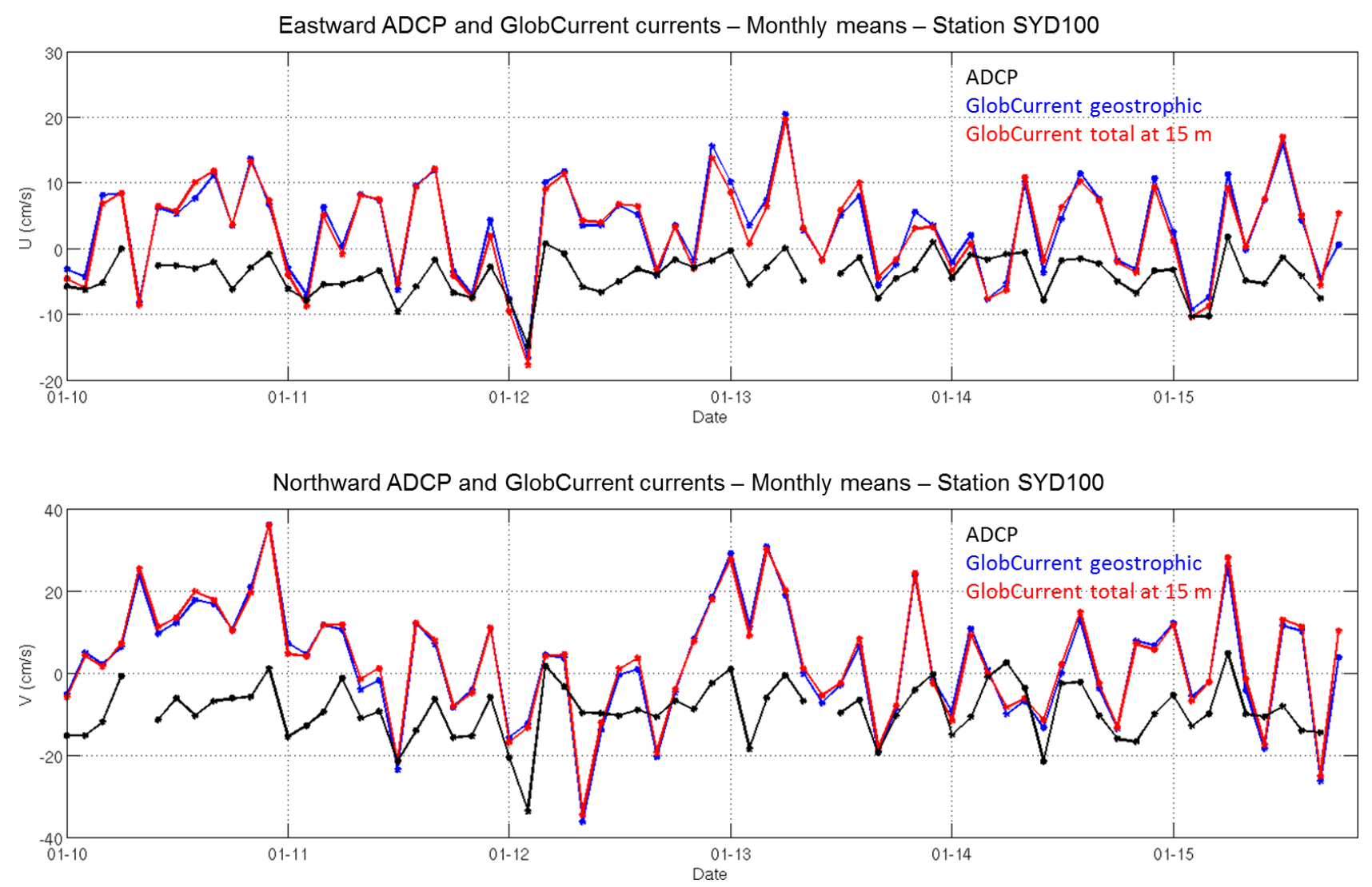

Figure 6: Monthly means of the ADCP currents (in black) and the GlobCurrent geostrophic currents (in blue) and total surface currents at $15 \mathrm{~m}$ (in red) at the SYD100 ADCP station. 

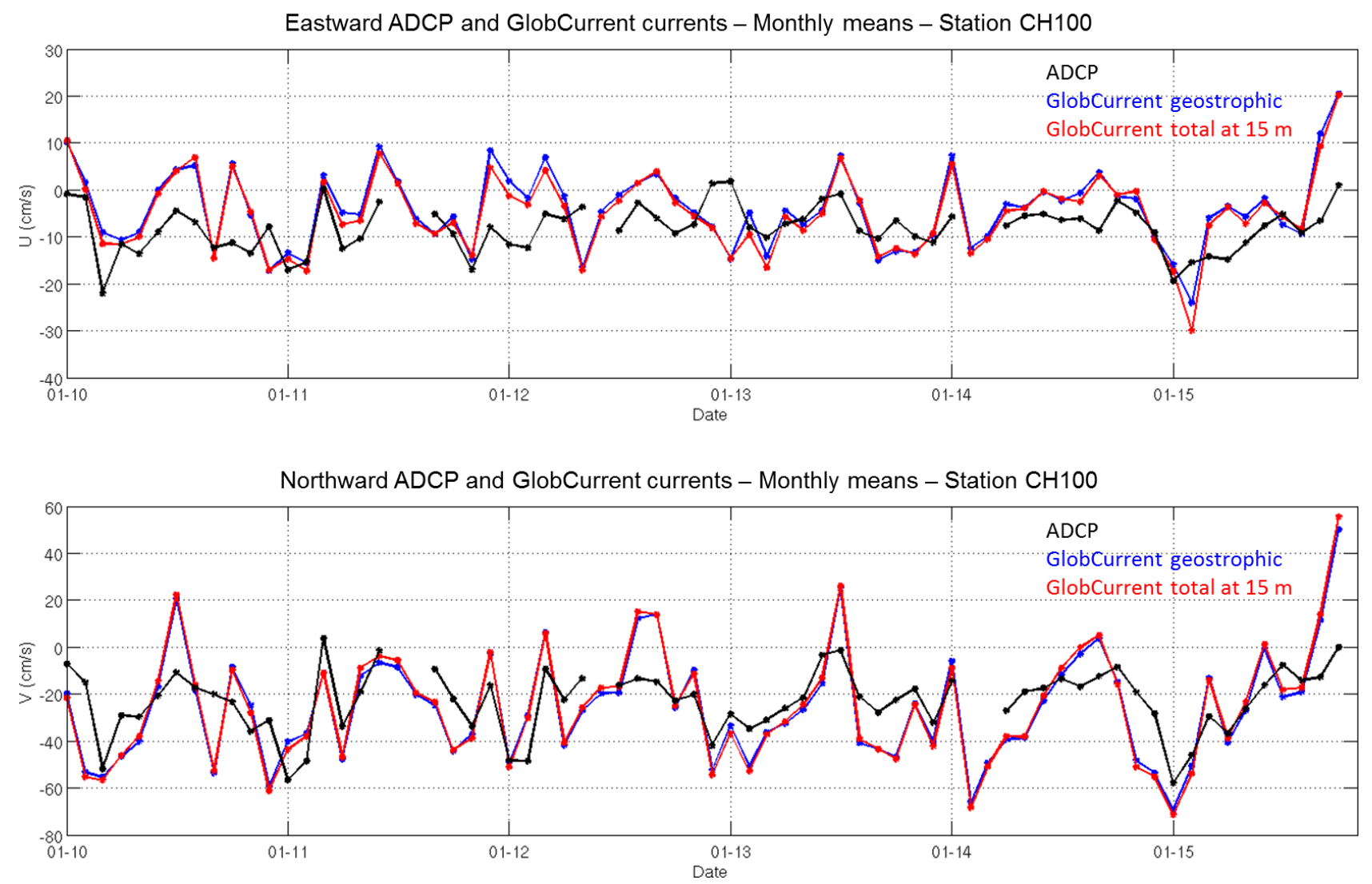

Figure 7 : Monthly means of the ADCP currents (in black) and the GlobCurrent geostrophic currents (in blue) and total surface currents at $15 \mathrm{~m}$ (in red) at the CH100 ADCP station.

\subsubsection{Offshore comparison with drifting buoys data}

To complete the coastal analysis and assess the performance of the GlobCurrent products in the open ocean, offshore comparisons were made with four drifting buoys in the EAC region. Because the GlobCurrrent 3-hourly total ocean currents products are designed for offshore applications, the aim of this offshore comparison was to put them to the test of the total ocean currents derived from the drifter trajectories. Thus no temporal filtering was applied to any of the datasets in order to keep the 3-hourly Ekman currents contribution in the GlobCurrent products (mainly diurnal and semi-diurnal signals as shown previously) for the comparison.

First, the velocities derived from the drifters trajectories were compared with the GlobCurrent total ocean currents at $15 \mathrm{~m}$, extracted at the positions and dates of the drifters, every 6 hours (Fig. 8). Note that the blue arrows of the GlobCurrent products are sometimes 
missing on the figures, when the drifter positions are out of the GlobCurrent grid. The nonfiltered ADCP velocities (in black in Fig. 8) were also extracted for the closest positions of the drifters. The very good agreement between the drifters and the ADCP data at all the ADCP stations confirms that the GlobCurrent products are generally not correct close to the Sydney stations in particular, as it was shown in the previous section.

For the four considered drifting buoys, Fig. 8 shows a general good agreement between the drifters currents and the GlobCurrent currents, in terms of directions. In particular, the large eddy structures described by drifters 101921 (Fig. 8 a) and 122612 (Fig. 8 b) are well represented in the GlobCurrent products. However, the GlobCurrent products generally lack energy, as the amplitude of the drifter currents is generally larger. 


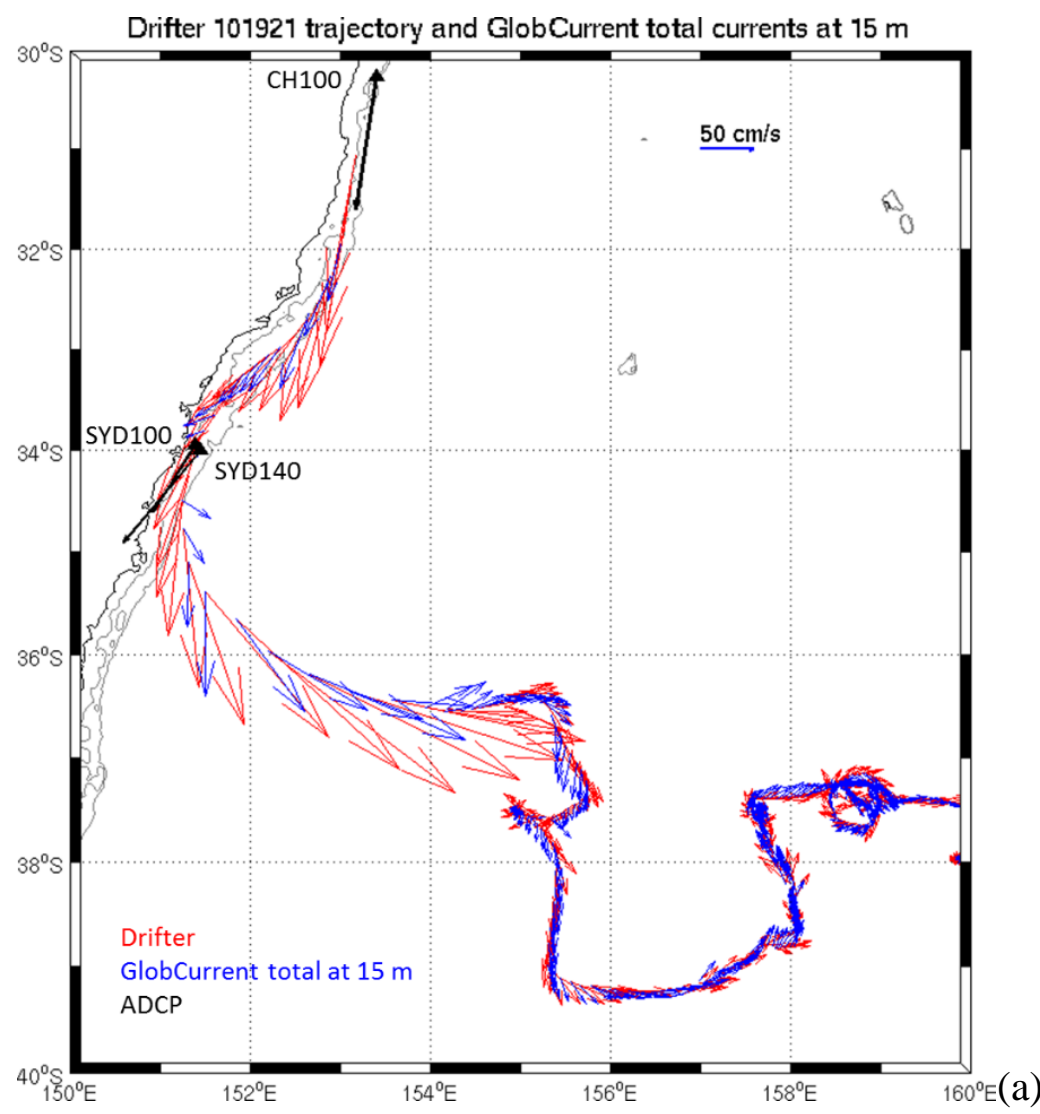

Drifter 122612 trajectory and GlobCurrent total currents at $15 \mathrm{~m}$

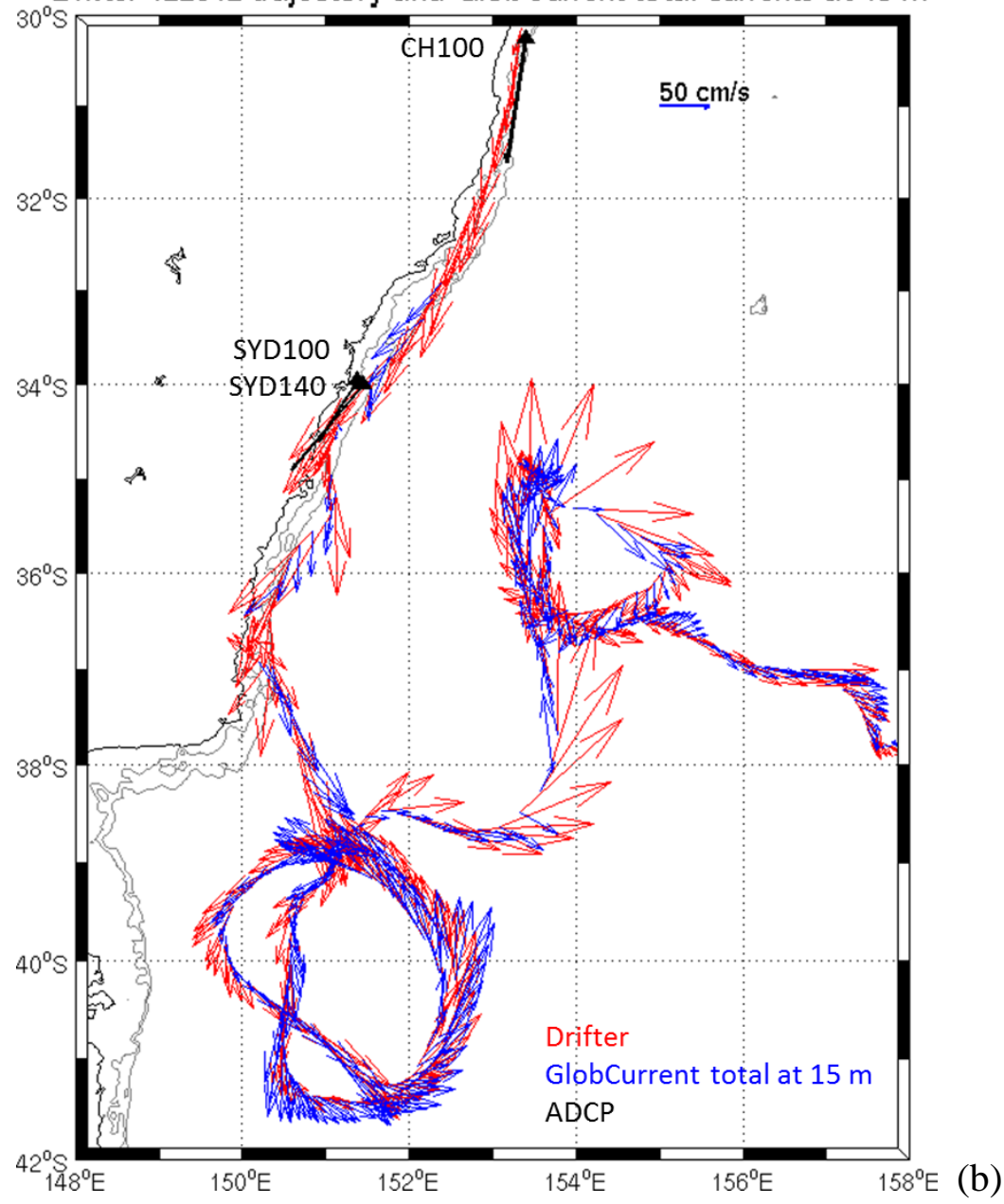




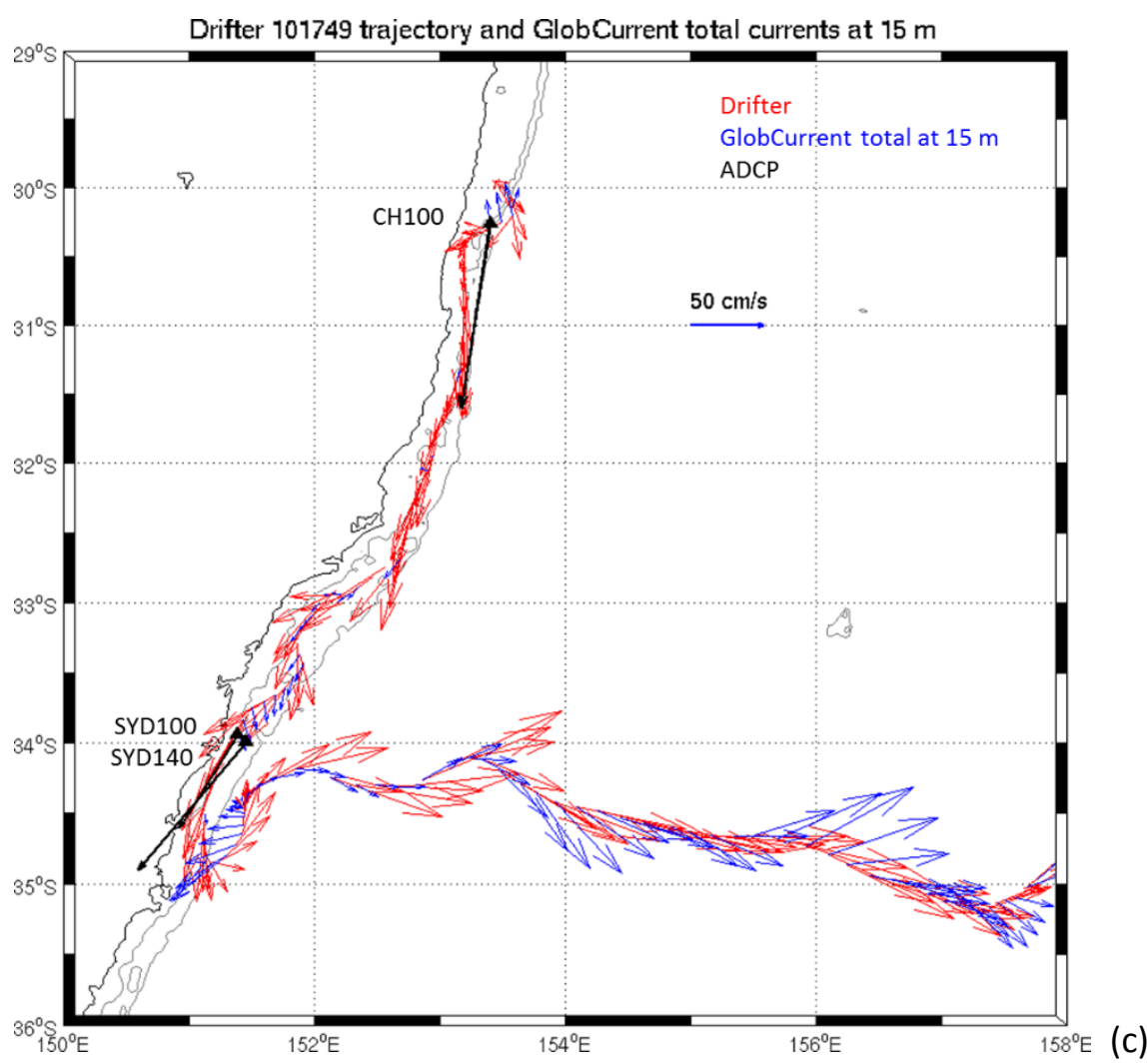

Drifter 139659 trajectory and GlobCurrent total currents at $15 \mathrm{~m}$

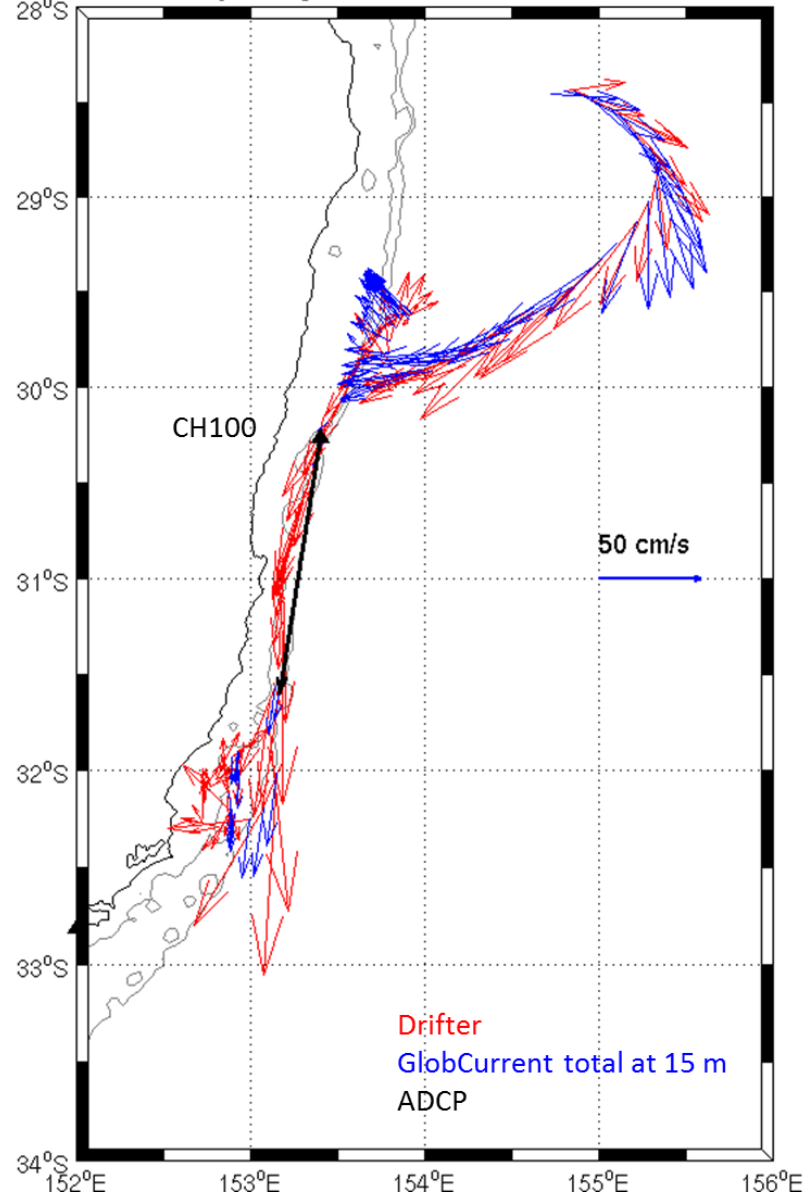

(d) 
Figure 8: Drifters trajectories and velocities (in red) and velocities of the GlobCurrent total currents at $15 \mathrm{~m}$ at the drifters positions (in blue). The ADCP velocities at the closest positions of the drifters are also shown (in black).

In order to characterize the consistency between the drifters and the GlobCurrent products with quantitative metrics, the skill scores of the GlobCurrent products were computed using the methodology proposed in Liu and Weisberg, 2011, and used in the Gulf of Mexico for several ocean current products in Liu et al, 2014. This non-dimensional skill score indicates the relative performance of the GlobCurrent products compared to the drifters observations and, as it is only based on the trajectories, no prior knowledge of the ocean circulation is needed.

For each position of the real drifters, the trajectories of pseudo-drifters were computed as if they were advected by the GlobCurrent products, either by the geostrophic currents alone or by the total ocean currents at $15 \mathrm{~m}$. As the GlobCurrent total currents at $15 \mathrm{~m}$ are provided 3-hourly, the computation of the pseudo-drifters advected by these fields was done using all the maps, at 3-hour temporal sampling. Indeed, even if the real drifter data are available every 6 hours, the real drifter undergoes ocean dynamics variations at higher frequency and it is fair to compare the pseudo-drifter trajectories using the full temporal resolution of the GlobCurrent products. On the other hand, the GlobCurrent geostrophic currents are provided daily and the position of the pseudo-drifter can only be computed for one point of four of the real drifter trajectory. Thus, the pseudo-drifters advected by the GlobCurrent geostrophic current fields are submitted to the same velocity and direction of the current during 24 hours, while the pseudodrifters advected by the GlobCurrent total current fields are potentially submitted to changes in the velocity and direction of the current every 3 hours.

The skill score (s) is defined by Liu and Weisberg (2011) as:

$\begin{cases}s=1-\frac{c}{n} & (c \leq n) \\ s=0 & (c>n)\end{cases}$

where 


$$
c=\frac{\sum_{i=1}^{N} d_{i}}{\sum_{k=1}^{M} l_{k}} \quad(\text { Eq. } 2)
$$

Starting from a given point of the real drifter trajectory, $\mathrm{N}$ is the number of GlobCurrent dates during the 3-day period following the date of the considered point ( $\mathrm{N}=3$ for the daily GlobCurrent geostrophic currents products and $\mathrm{N}=3 * 8=24$ for the 3-hourly GlobCurrent total currents products), $\mathrm{M}$ is the number of 6-hourly drifter dates during the same 3-day period $(\mathrm{M}=3 * 4=12)$ and $\mathrm{c}$ is the cumulative Lagrangian separation distance (d) divided by the cumulative length of the observed trajectory (1). The tolerance threshold $\mathrm{n}$ is set to 1 as suggested by Liu and Weisberg, 2011. Thus, the skill score can be written as follows: $\begin{cases}s=1-c & (c \leq 1) \\ s=0 & (c>1)\end{cases}$

Pseudo-drifters with c $>1$ correspond to a cumulative separation distance larger than the cumulative length of the observed trajectory. When $s=1$, the test dataset is considered to be perfectly skilled.

Fig. 9 to 12 show the skill scores in color scale during a 3-day period for each of the four drifters considered in this work. The trajectories of drifter 101921 (Fig. 9) and drifter 122612 (Fig. 10) are of particular interest as they present a large variety of structures, flowing along the EAC and then curling around eddies. For these two cases, the skill scores were computed for both GlobCurrent products, the geostrophic currents ((a) plots) and the total currents at $15 \mathrm{~m}$ ((b) plots). For the two other drifters (Fig. 11 and Fig. 12), the skill scores are only shown for the GlobCurrent total currents. On each plot, the observed drifter trajectory is shown with a black dotted line and the light gray lines show the trajectories of the pseudodrifters during the 3-day period following their launch.

As expected, the skill scores are very low or equal to zero when the drifters are close to the New South Wales coast. In most of these cases, the pseudo-drifters end up on the shore or fall out of the GlobCurrent grid. For example, the pseudo-drifters launched at about $33.5^{\circ} \mathrm{S}$ on 
the path of drifter 101921 are systematically pushed to the shore whereas the real drifter continues its way southward, following the EAC stream (Fig. 9 (a) and (b)). This is consistent with the findings of the previous section, where the comparisons to the ADCP data along this coast revealed that the GlobCurrent products, and the MDT on which they are based, show unrealistic counter-currents in this area.

When the drifters stay in the EAC stream relatively far from the coast, especially between $30^{\circ} \mathrm{S}$ and $34^{\circ} \mathrm{S}$, the skill scores increase to 0.6 or 0.7 as the pseudo-drifters are mainly advected by the EAC (drifter 101921 between $32^{\circ} \mathrm{S}$ and $33^{\circ} \mathrm{S}$ (Fig. 9), drifter 122612 between $33^{\circ} \mathrm{S}$ and $34^{\circ} \mathrm{S}$ (Fig. 10) and drifter 139659 between $31^{\circ} \mathrm{S}$ and $32^{\circ} \mathrm{S}$ (Fig. 12)). The comparison between the GlobCurrent geostrophic currents and the GlobCurrent total currents at $15 \mathrm{~m}((\mathrm{c})$ plots on Fig. 9 and Fig. 10) shows that the skill scores in the EAC stream are generally slightly better when considering the GlobCurrent geostrophic currents only. This is probably mainly due to the lower temporal resolution of the GlobCurrent geostrophic-only currents, which induces that the pseudo-drifters are advected along the EAC main stream with the same current amplitude and direction over a 24-hour period instead of 3 hours for the total currents estimates, with less chance to be pushed to the shore. The 3-hourly GlobCurrent Ekman current contribution does not improve the description of the EAC in this region, mainly because of its coarse spatial resolution close to the coast.

Regarding the other structures that are described by the four drifters in the region, the skill scores of the GlobCurrent products are rather satisfactory (ranging between 0.6 and 0.9 ) on large eddy structures, such as for drifter 101921 (Fig. 9) and drifter 122612 (Fig. 10). The scores are generally lower in the areas of rapid direction change or in regions of divergences, where the pseudo-drifters sometimes catch streamlines that are completely different from the real drifter trajectory. This is the case for drifter 139659 (Fig. 12), when the pseudo-drifters continue to curl around the cyclonic eddy structure located between $28.5^{\circ} \mathrm{S}$ and $30^{\circ} \mathrm{S}$ instead of 
entering the EAC southward path like the real drifter. In the same way, the last observed positions, between $32^{\circ} \mathrm{S}$ and $32.5^{\circ} \mathrm{S}$, show that this drifter turns to the West and then heads to the North following a retroflection along the coast that is clearly not present in the GlobCurrent products as all the pseudo-drifters continue their ways southward.

As already mentioned above, the trajectory of drifter 101921 is of particular interest as it describes a variety of oceanic features of different sizes. This is thus a good test-bed for the GlobCurrent products. Fig. 13 highlights in colored boxes the four features of interest that are analyzed hereafter:

- A: the East Australian Current path;

- B and C: two large (300-km diameter) anti-cyclonic eddies;

- D: a smaller (100-km diameter) cyclonic eddy.

In order to assess the performance of the GlobCurrent products on these four oceanic features, Fig. 14 shows the GlobCurrent fields and the positions of seven pseudo-drifters advected by these current fields (one color for each pseudo-drifter) for a selection of dates. The positions of the real drifter are shown in black. The left plots show the pseudo-drifters advected by the GlobCurrent geostrophic currents and the right plots show the pseudo-drifters advected by the GlobCurrent total currents.

The first maps on Fig. 14 (20/02/2013) show that the red pseudo-drifter, launched in the EAC (feature A on Fig. 13) on the 14/02/2013, is maintained a bit farther from the coast by the GlobCurrent streamlines as it flows along the EAC path about $30 \mathrm{~km}$ East from the real drifter. In terms of speed, the GlobCurrent currents are very consistent with the real drifter in the EAC path, whatever the products, down to $34^{\circ} \mathrm{S}$.

There, the velocity of the real drifter increases while it curls around the large anticyclonic eddy (feature B on Fig. 13). In the GlobCurrent products, the diameter of this eddy feature is quite consistent with the real drifter trajectory. However, in terms of position, the 
eddy appears to be a little shifted southwestward in the GlobCurrent products, as the real drifter trajectory goes through its most southwestern part, at $152^{\circ} \mathrm{E}$. The pseudo-drifter advected by the GlobCurrent total currents sticks better to the real drifter trajectory around the eddy feature $\mathrm{B}$, thanks to the Ekman current contribution and to the higher temporal resolution of these fields. However, the velocities of both GlobCurrent products are clearly underestimated from $34^{\circ} \mathrm{S}$, in the eddy feature $\mathrm{B}$, as the pseudo-drifters advected by the GlobCurrent total currents and by the GlobCurrent geostrophic currents are respectively $200 \mathrm{~km}$ and $300 \mathrm{~km}$ behind the real drifter on the 20/02/2013. These observations are in agreement with the low skill scores (0.3 or 0.4 ) obtained in this region, as shown on Fig. 9.

The orange pseudo-drifter on Fig. 14 was launched a few hours before the real drifter left the eddy feature B to enter the eddy feature C (Fig. 13). In this region, the GlobCurrent total current streamlines are quite consistent with the real drifter trajectory, including the sharp $90^{\circ}$ turn that occurs on the $24 / 02 / 2013$ at $155^{\circ} \mathrm{E}$ and $36.5^{\circ} \mathrm{S}$ (Fig. 14). There, the skill scores of the GlobCurrent total current product are rather good, ranging between 0.6 and 0.8 (Fig. 9). This is clearly due to the Ekman current contribution (shown on Fig. 15), that drives the two (red and orange) pseudo-drifters in the southward direction, whereas the two pseudo-drifters advected only by the geostrophic currents heads northeastward, following a completely different path, far from the real drifter trajectory (Fig. 14, maps of 26/02/2013).

The GlobCurrent total currents map on the 08/03/2013 (Fig. 14) shows that the two pseudo-drifters then turned to the West, like the real drifter. However, in the case of the pseudodrifters, this turn happened at $37^{\circ} \mathrm{S}$, about $50 \mathrm{~km}$ more North than the turn of the real drifter. Then the pseudo-drifters caught strong eastward streamlines and left the path of the real drifter. On the other hand, the real drifter stayed a few days in this area of divergence and described a small loop that is not so well represented in the GlobCurrent products, as confirmed by the low skill scores on Fig. 9. 
The yellow pseudo-drifter and the green pseudo-drifter (Fig. 14, maps of 26/03/2013) were launched while the real drifter was curling around the eddy feature $\mathrm{C}$ indicated on Fig. 13. For this large eddy feature, like previously shown for eddy feature B, the paths of the pseudodrifters advected by the GlobCurrent fields are quite consistent with the real drifter trajectory, in terms of position, diameter and velocity, whatever the GlobCurrent fields. The large skill scores in the region confirm these observations (Fig. 9). Local decreases in the skill scores are due to some rapid changes in direction of the real drifter trajectory. One can also note that while the drifter heads North along the eddy feature C, between $38.5^{\circ} \mathrm{S}$ and $37.5^{\circ} \mathrm{S}$, it is about $75 \mathrm{~km}$ behind the green pseudo-drifter on the 26/03/2013 (Fig. 14), whatever the GlobCurrent fields, which means that the GlobCurrent velocities are overestimated by about $20 \mathrm{~cm} / \mathrm{s}$.

Finally, the smaller eddy feature D indicated on Fig. 13 is present in both GlobCurrent products, as shown on the maps of 03/05/2013 (Fig. 14). The real drifter curls twice around this eddy. In the meantime, the pseudo-drifters launched in this area describe one loop and a half around the eddy. The GlobCurrent velocities are consequently underestimated over this eddy but the position and diameter are quite consistent with the real drifter trajectory. The paths of the pseudo-drifters advected by the GlobCurrent total currents are closer to the real drifter path, as they benefit from higher frequency updates of their positions and velocities (every 3 hours) than the pseudo-drifters advected by the GlobCurrent geostrophic currents (once a day). Again the skill score results shown on Fig. 9 confirm these observations, as well as the analysis of the skill scores for the three other drifters (Fig. 10, Fig. 11, Fig. 12): the smaller the ocean dynamics structures, the lower the skill scores, which is in good agreement with the intrinsic spatiotemporal resolution of the GlobCurrent products. 

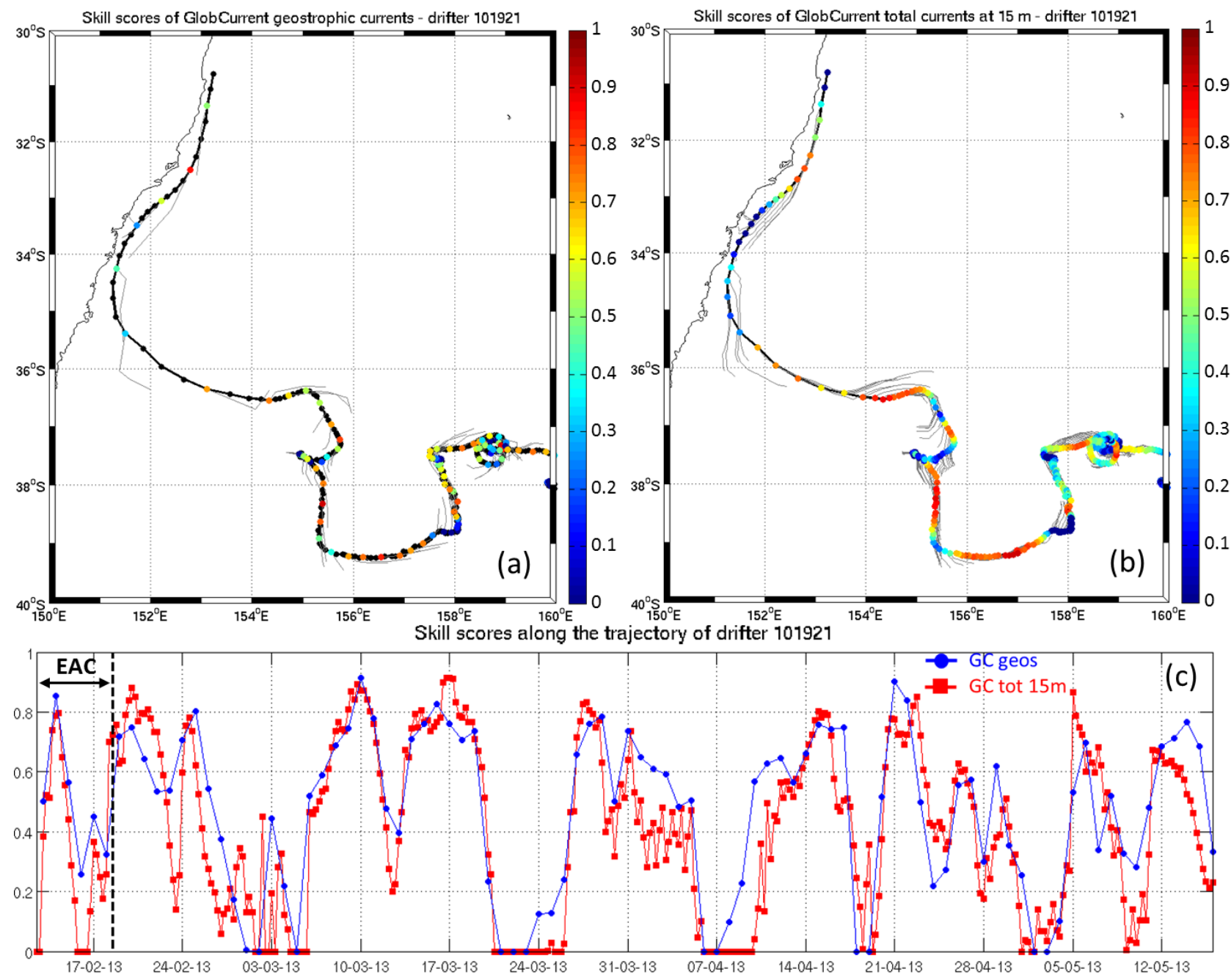

Figure 9: Skill scores (in color) after 3 days of advection with the GobCurrent products ((a) geostrophic currents and (b) total currents at $15 \mathrm{~m}$ ). The black dotted line shows the positions of the real drifter (101921). The light gray lines show the positions of the pseudo-drifters launched at each position of the real drifter and after 3 days of advection by the GlobCurrent maps. Below (c), time series of the skill scores along the drifter trajectory, for the GlobCurrent geostrophic currents in blue and the GlobCurrent total currents at $15 \mathrm{~m}$ in red. The black dashed vertical line shows the moment when the drifter leaves the East Australian Current (EAC). 

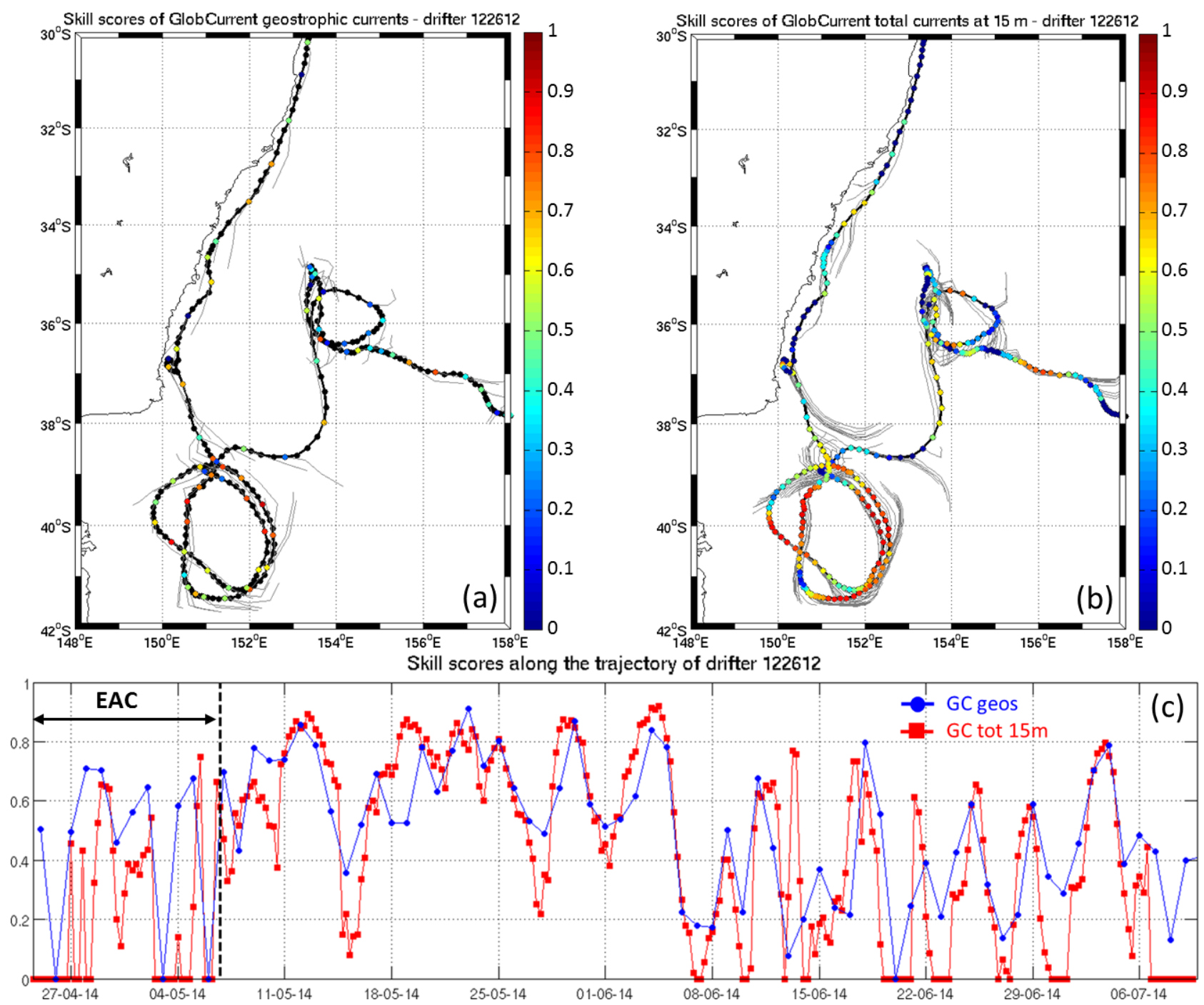

Figure 10: Skill scores (in color) after 3 days of advection with the GobCurrent products ((a) geostrophic

currents and (b) total currents at $15 \mathrm{~m}$ ). The black dotted line shows the positions of the real drifter (122612).

The light gray lines show the positions of the pseudo-drifters launched at each position of the real drifter and after 3 days of advection by the GlobCurrent maps. Below (c), time series of the skill scores along the drifter trajectory, for the GlobCurrent geostrophic currents in blue and the GlobCurrent total currents at $15 \mathrm{~m}$ in red. The black dashed vertical line shows the moment when the drifter leaves the East Australian Current (EAC). 


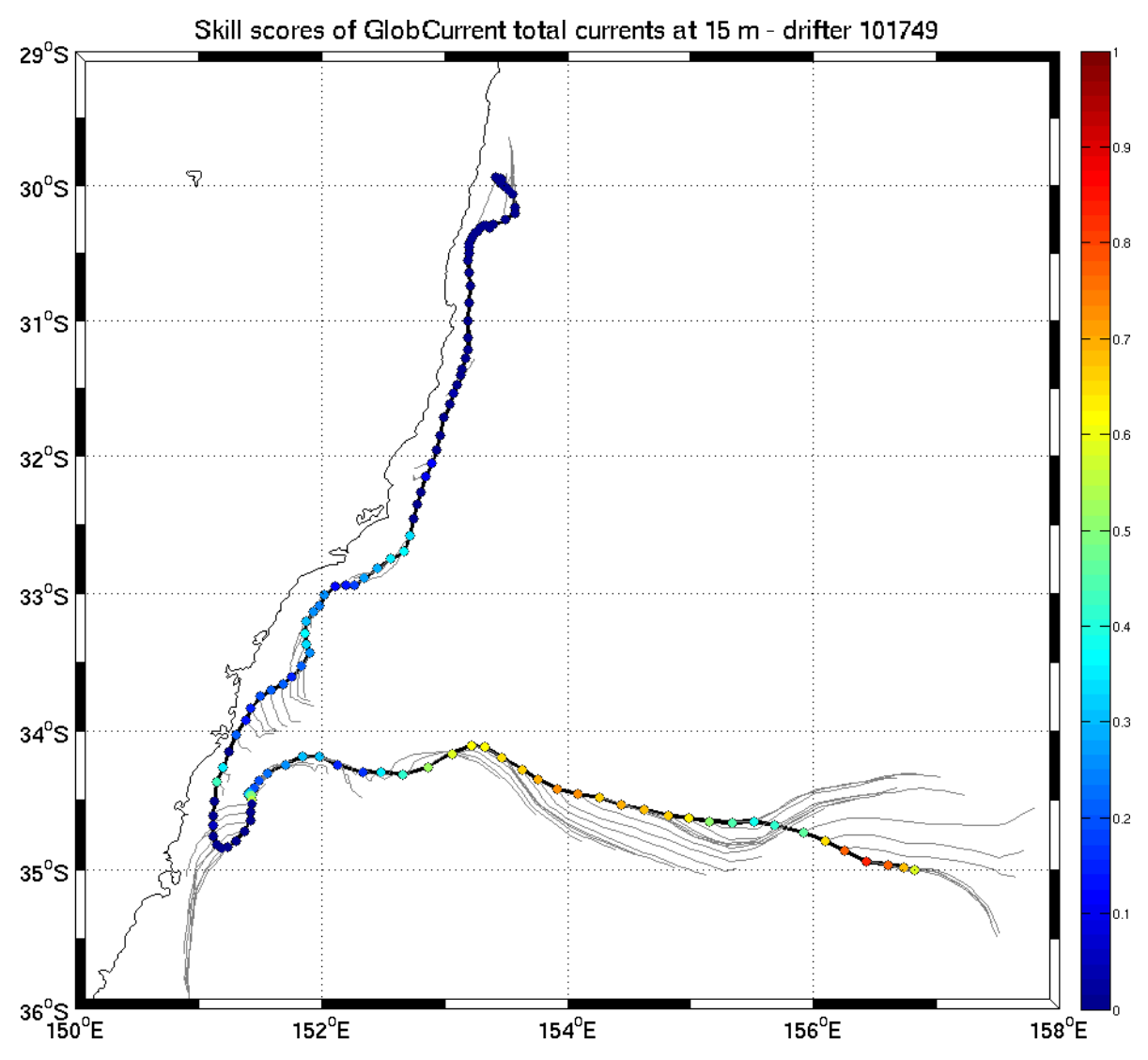

Figure 11 : Skill scores (in color) after 3 days of advection with the GobCurrent total currents at $15 \mathrm{~m}$. The black dotted line shows the positions of the real drifter (101749). The light gray lines show the positions of the pseudo-drifters launched at each position of the real drifter and after 3 days of advection by the GlobCurrent maps. 


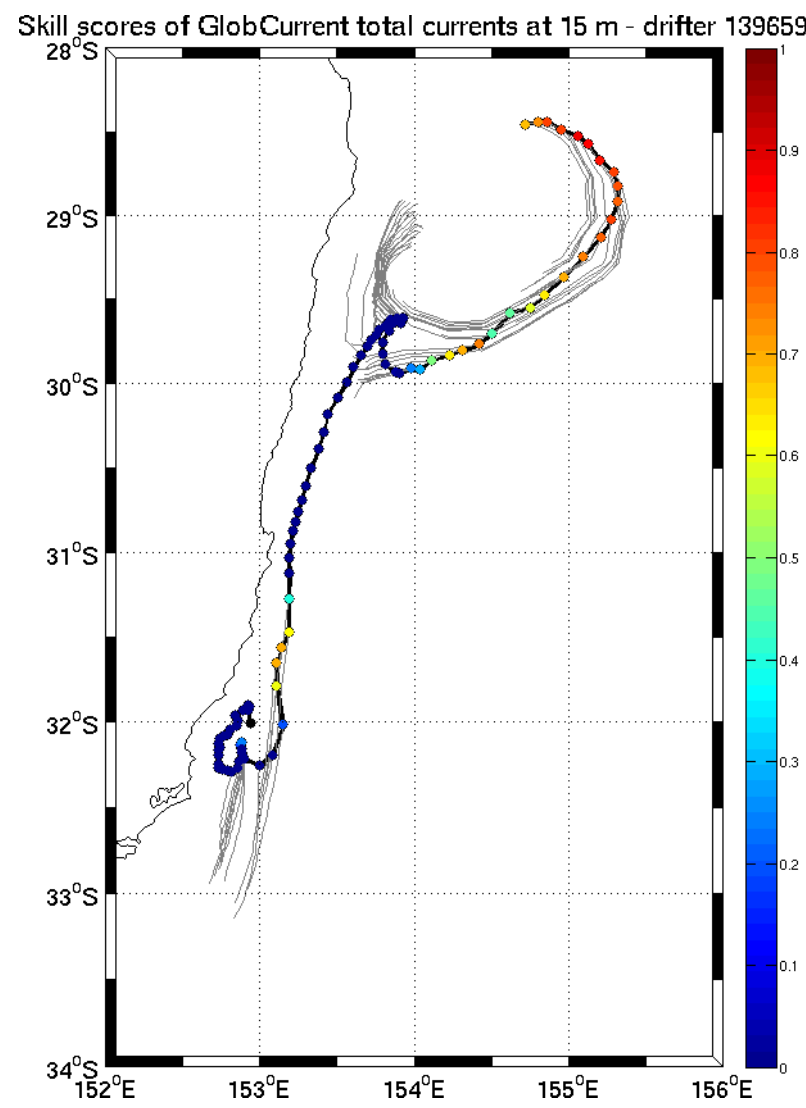

Figure 12: Skill scores (in color) after 3 days of advection with the GobCurrent total currents at 15 m. The black dotted line shows the positions of the real drifter (139659). The light gray lines show the positions of the pseudodrifters launched at each position of the real drifter and after 3 days of advection by the GlobCurrent maps. 


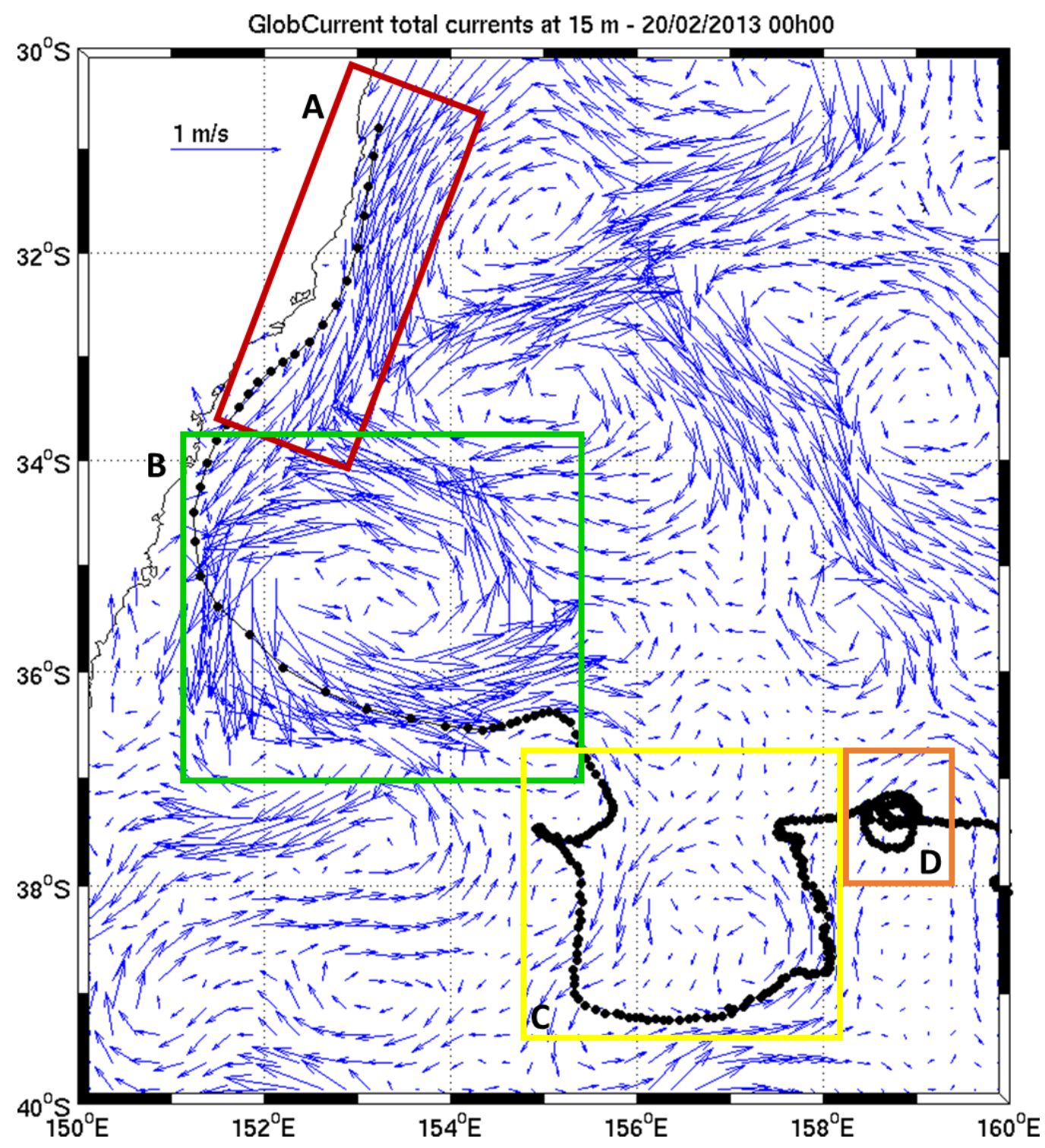

Figure 13: GlobCurrent total current field (blue arrows) on the 20/02/2013 at 00:00 and positions of drifter 101921(black dots) from the 13/02/2013 to the 16/05/2013. The four boxes in color (A, B, C and D) show the features of interest for the analysis of the GlobCurrent products. 

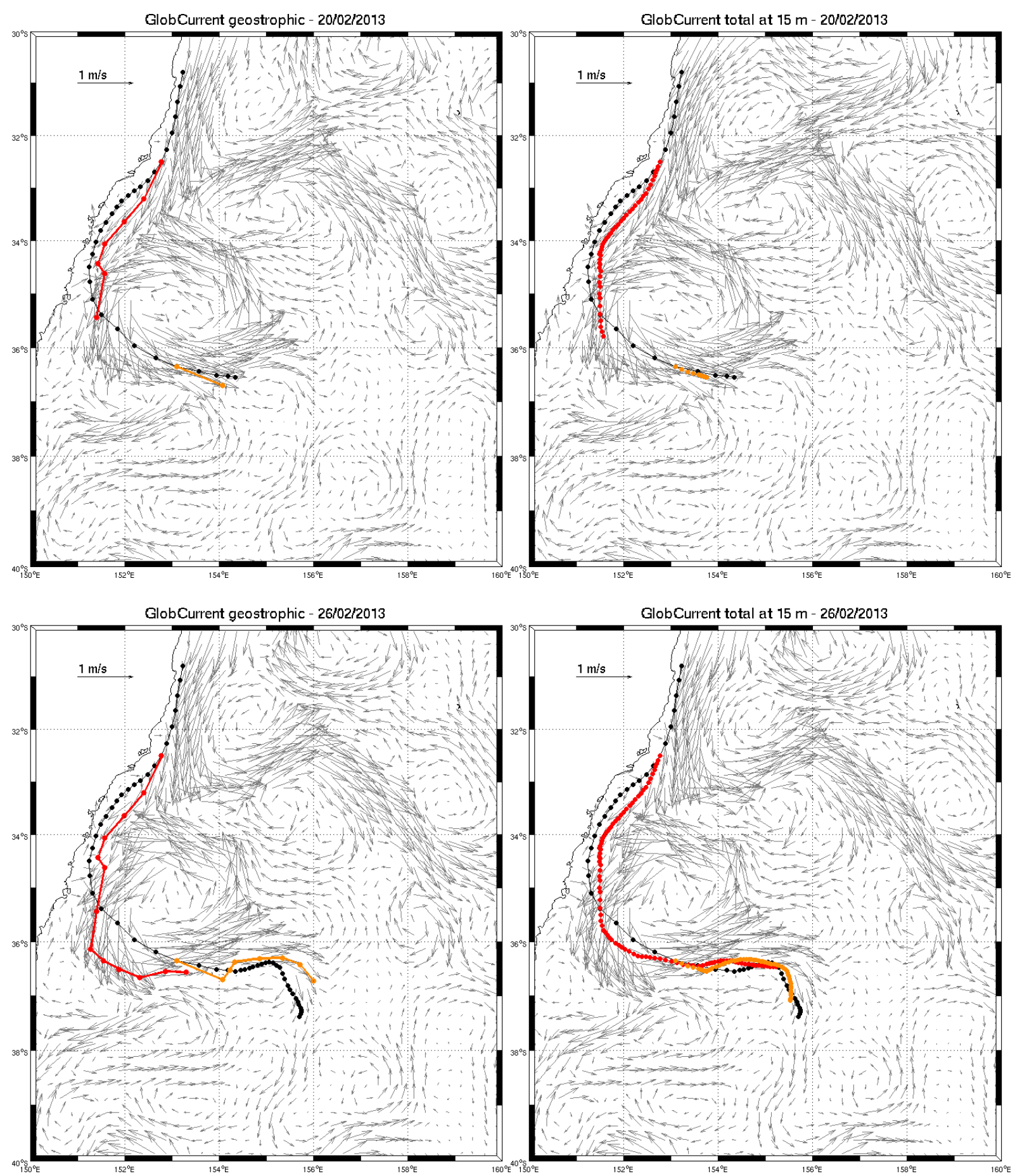

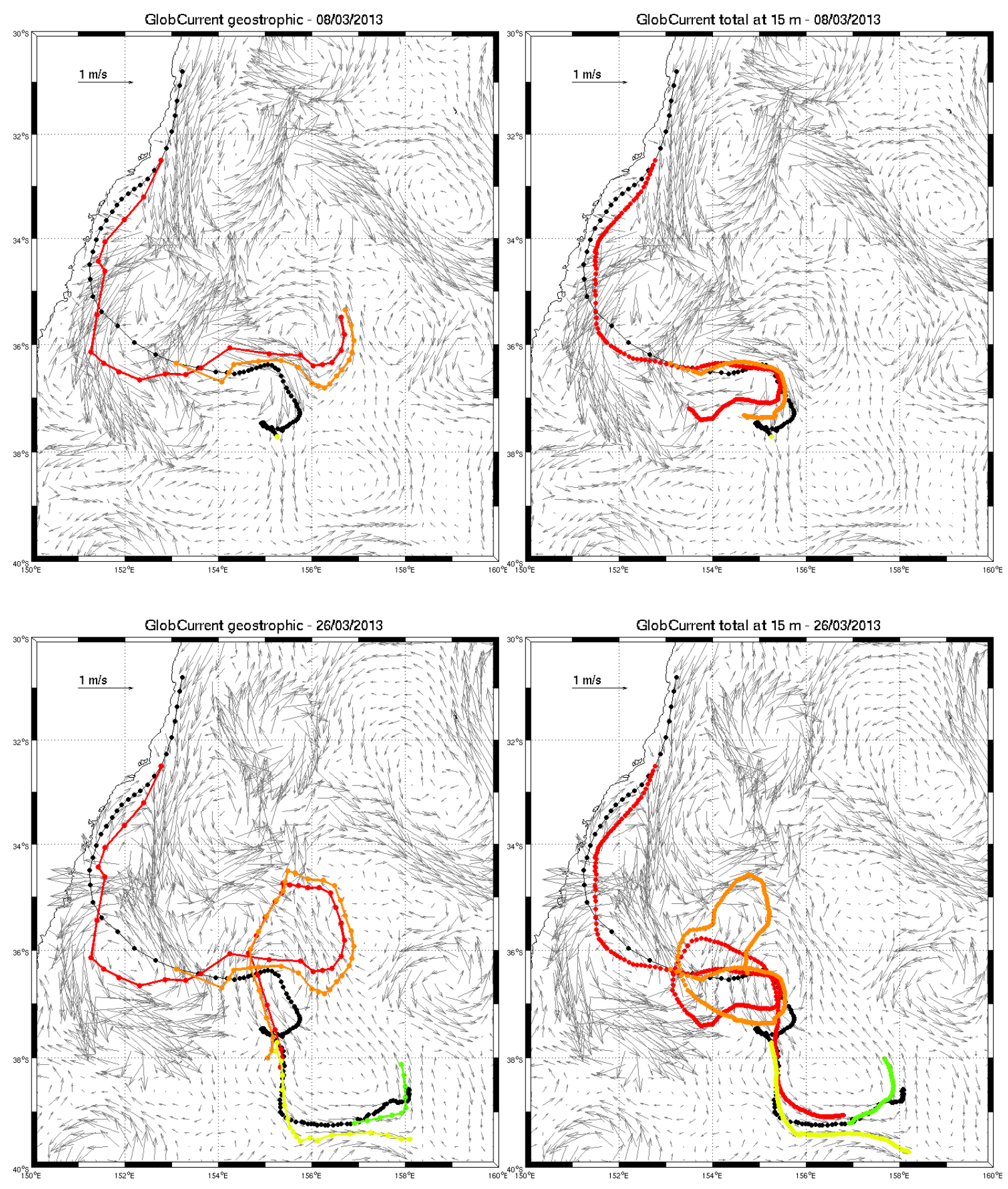


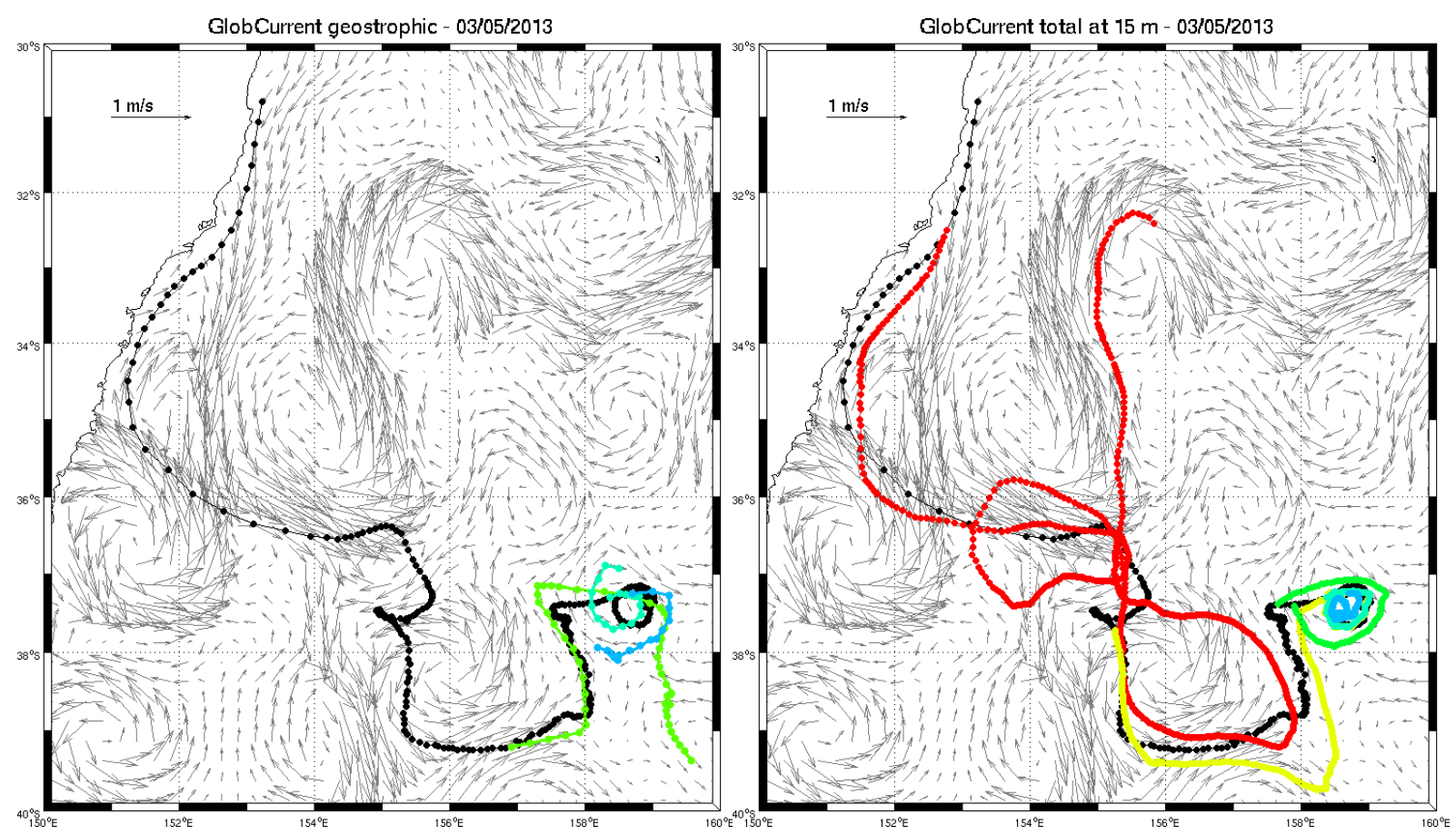

Figure 14: Trajectories over the time of pseudo-drifters (in color) advected by the fields of GlobCurrent total surface currents at $15 \mathrm{~m}$ (right plot) or GlobCurrent geostrophic currents (left plot). The positions of the real drifter (101921) are in black. The GlobCurrent velocity fields used to advect the pseudo-drifters are shown with gray arrows. 


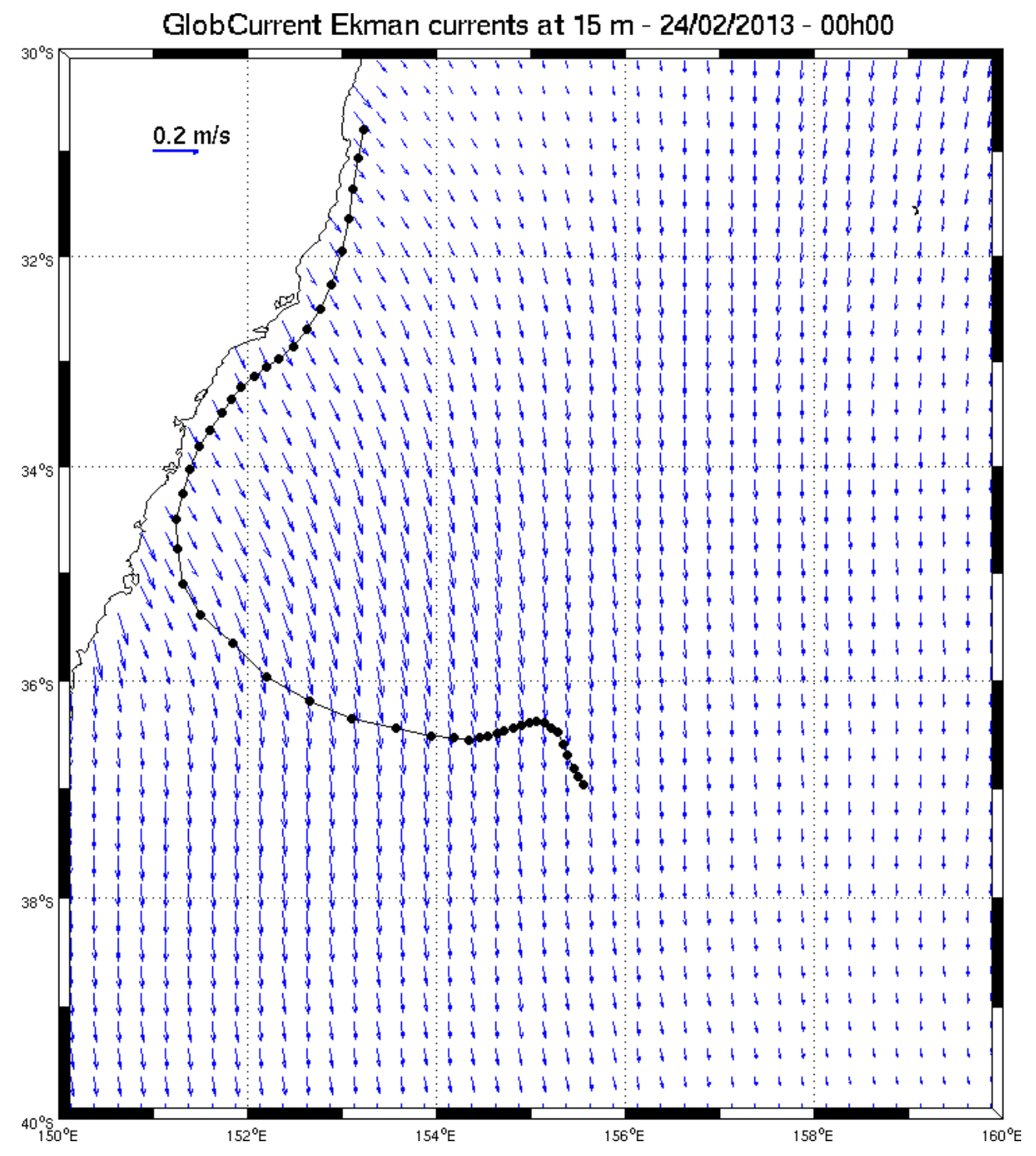

Figure 15: GlobCurrent Ekman current field (blue arrows) on the 24/02/2013 at 00:00 and path of drifter 101921(black dotted line) from the 13/02/2013 to the 24/02/2013.

\subsection{Assessment in a macro-tidal region: the Joseph Bonaparte Gulf}

The Joseph Bonaparte Gulf is located on a 500-km wide shelf in the northwest part of Australia, close to Darwin, between the Timor and Arafura Seas (Fig. 16). The ocean tides in this region reach some of the largest amplitudes that can be observed around Australia, with about $10 \mathrm{~m}$ range. The tidal currents are consequently strong in this macro-tidal region and they 
can reach more than $1 \mathrm{~m} / \mathrm{s}$. The tidal currents are not provided in the GlobCurrent products (v3.0). Here we quantify the error associated with this missing component in the GlobCurrent products as well as we assess the accuracy of the GlobCurrent estimates of sub-tidal variability.

The three ADCP stations considered in this study are the Margaret Harries Banks (ITFMHB) station, the Flat Top Banks (ITFFTB) station and the Joseph Bonaparte Gulf (ITFJBG) station. They are located in the Joseph Bonaparte Gulf, at about 200m, 100m and 50m depth, respectively. The tidal currents at the ADCP stations were computed by applying tidal harmonic analysis to the ADCP raw currents time series at $15 \mathrm{~m}$ depth, for both current directions separately. The five main tidal components in the region (M2, K1, S2, O1 and N2) were extracted in the tidal harmonic analysis, as the amplitudes of the other tidal components were in the data noise level. The GlobCurrent total currents at $15 \mathrm{~m}$ were extracted at each ADCP station location. In this region, the mean geostrophic current is very low, as shown in Fig. 16, and the tidal currents are dominant, reaching more than $50 \mathrm{~cm} / \mathrm{s}$, as shown by the tidal current ellipses in Fig. 17 and by the time series extract at the ITFFTB station in Fig. 18. This is confirmed by the very low correlations between the GlobCurrent total currents and the ADCP total currents (Tab. 2).

As the GlobCurrent total current products do not include the tidal currents, they are potentially comparable to the de-tided ADCP observations. However, even after removing the main tidal currents, the ADCP data still contain high-frequency ocean dynamics signals such as inertial currents and remaining tidal currents from tidal components with low signal to noise ratio. Both datasets were consequently filtered with a 30-day low-pass filter, as previously done in the EAC region.

Filtering the GlobCurrent total currents and the ADCP detided currents slightly improves the correlations at the ITFFTB and ITFMHB stations, mainly in the eastward and in the northward directions, respectively (Tab. 2). However, there is still no clear agreement 
between the two datasets, whatever the direction of the current and the ADCP station (Fig. 19). At the ITFJBG station, the filtered GlobCurrent products globally show larger amplitudes than the ADCP data, with some differences of about $30 \mathrm{~cm} / \mathrm{s}$ between the two datasets, in both directions. In addition, the GlobCurrent products seem to contain some signal of roughly onemonth period, which is not visible in the ITFJBG ADCP current time series. Maps of the GlobCurrent geostrophic currents confirm that they contain strong unrealistic current features on the shelf (Fig. 20), with larger amplitudes even than the tidal signal.

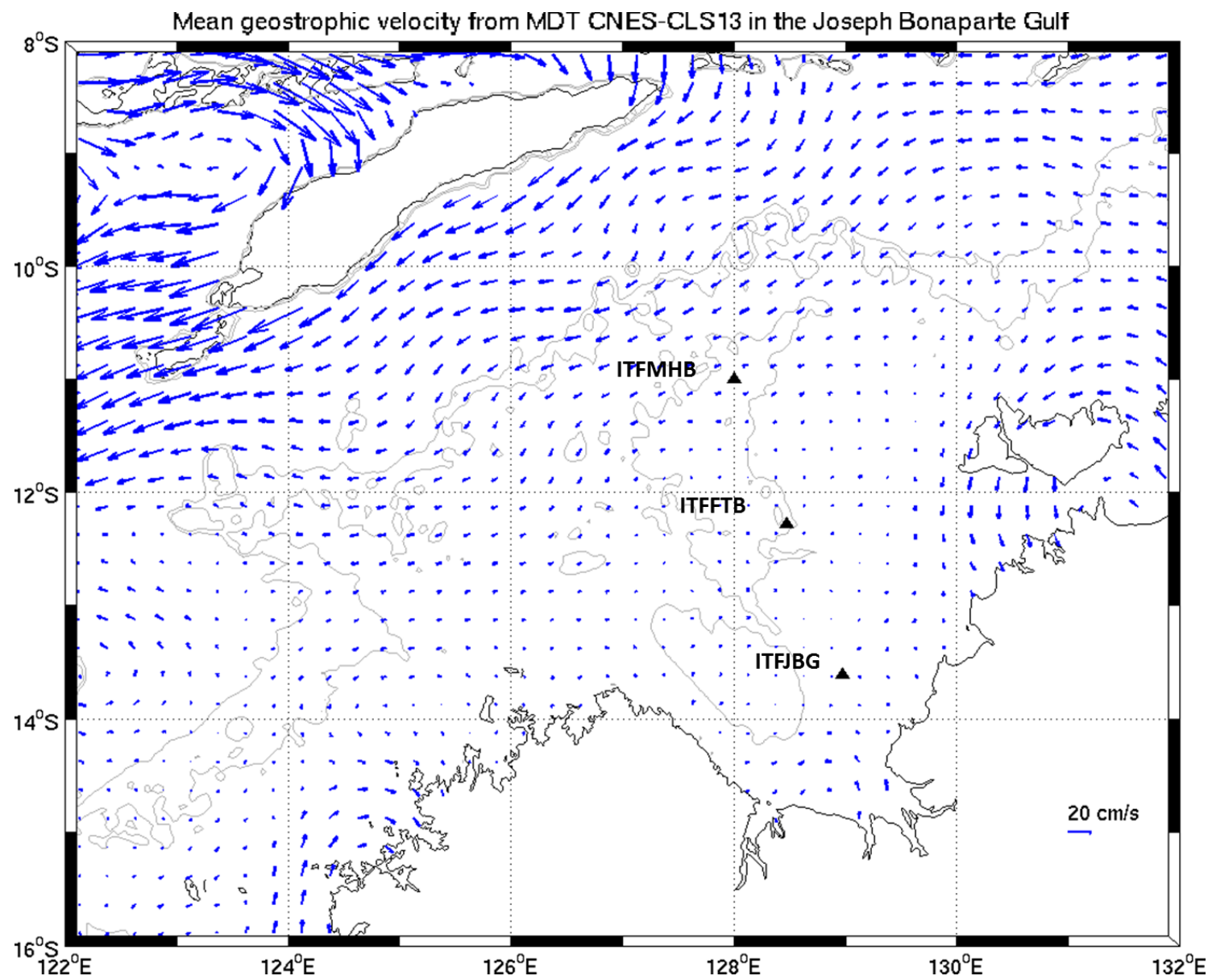

Figure 16 : Mean geostrophic velocities from the CNES-CLS13 1/4 ${ }^{\circ}$ Mean Dynamic Topography in the Joseph Bonaparte Gulf. The location of the three ADCP stations are shown with black triangles. The light gray lines show the $100 \mathrm{~m}$ and $200 \mathrm{~m}$ isobaths. 


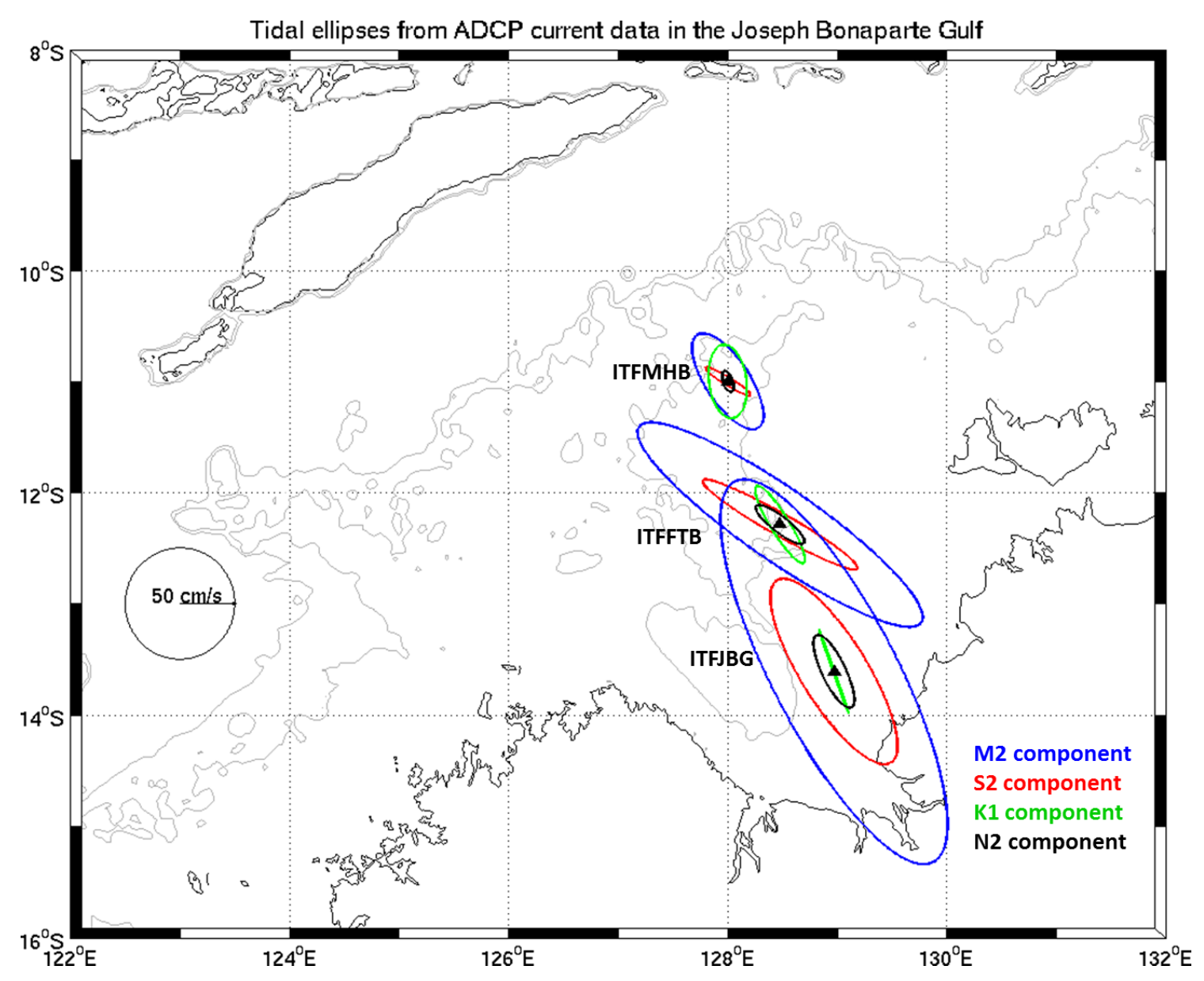

Figure 17: Tidal current ellipses for the four main tidal components (M2, S2, K1 and N2) extracted from the

ADCP current time series at 15-m depth. The location of the three ADCP stations are shown with black triangles. The light gray lines show the $100 \mathrm{~m}$ and $200 \mathrm{~m}$ isobaths.

Table 2: Statistics computed for the comparison between the GlobCurrent total surface currents and the ADCP observations in the Joseph Bonaparte Gulf. The correlations are computed for each current direction separately (U-eastward, $V$-northward) and on the current norm. The RMS differences and the biases are computed on the current norm only, following the convention (GlobCurrent data-ADCP data).

\begin{tabular}{|c|c|c|c|c|c|c|c|c|c|c|}
\hline \multirow[t]{3}{*}{ ADCP station } & \multicolumn{5}{|c|}{ Non-filtered total currents } & \multicolumn{5}{|c|}{ 30-day filtered detided currents } \\
\hline & \multicolumn{3}{|c|}{ Correlation } & \multirow{2}{*}{$\begin{array}{c}\text { RMS diff. } \\
(\mathrm{m} / \mathrm{s})\end{array}$} & \multirow{2}{*}{$\begin{array}{l}\text { Bias } \\
(\mathrm{m} / \mathrm{s})\end{array}$} & \multicolumn{3}{|c|}{ Correlation } & \multirow{2}{*}{$\begin{array}{l}\text { RMS } \\
\text { diff. } \\
(\mathrm{m} / \mathrm{s})\end{array}$} & \multirow{2}{*}{$\begin{array}{l}\text { Bias } \\
(\mathrm{m} / \mathrm{s})\end{array}$} \\
\hline & $U$ & $\mathbf{V}$ & Norm & & & $U$ & $\mathbf{V}$ & $\begin{array}{c}\text { Nor } \\
\mathrm{m}\end{array}$ & & \\
\hline ITFJBG & 0.03 & 0.00 & 0.10 & 0.31 & 0.08 & 0.16 & -0.03 & 0.05 & 0.18 & 0.30 \\
\hline ITFFTB & 0.06 & 0.06 & 0.07 & 0.16 & -0.11 & 0.42 & 0.27 & 0.11 & 0.06 & 0.06 \\
\hline ITFMBH & 0.15 & 0.22 & 0.10 & 0.11 & -0.03 & 0.24 & 0.48 & 0.12 & 0.07 & 0.03 \\
\hline
\end{tabular}



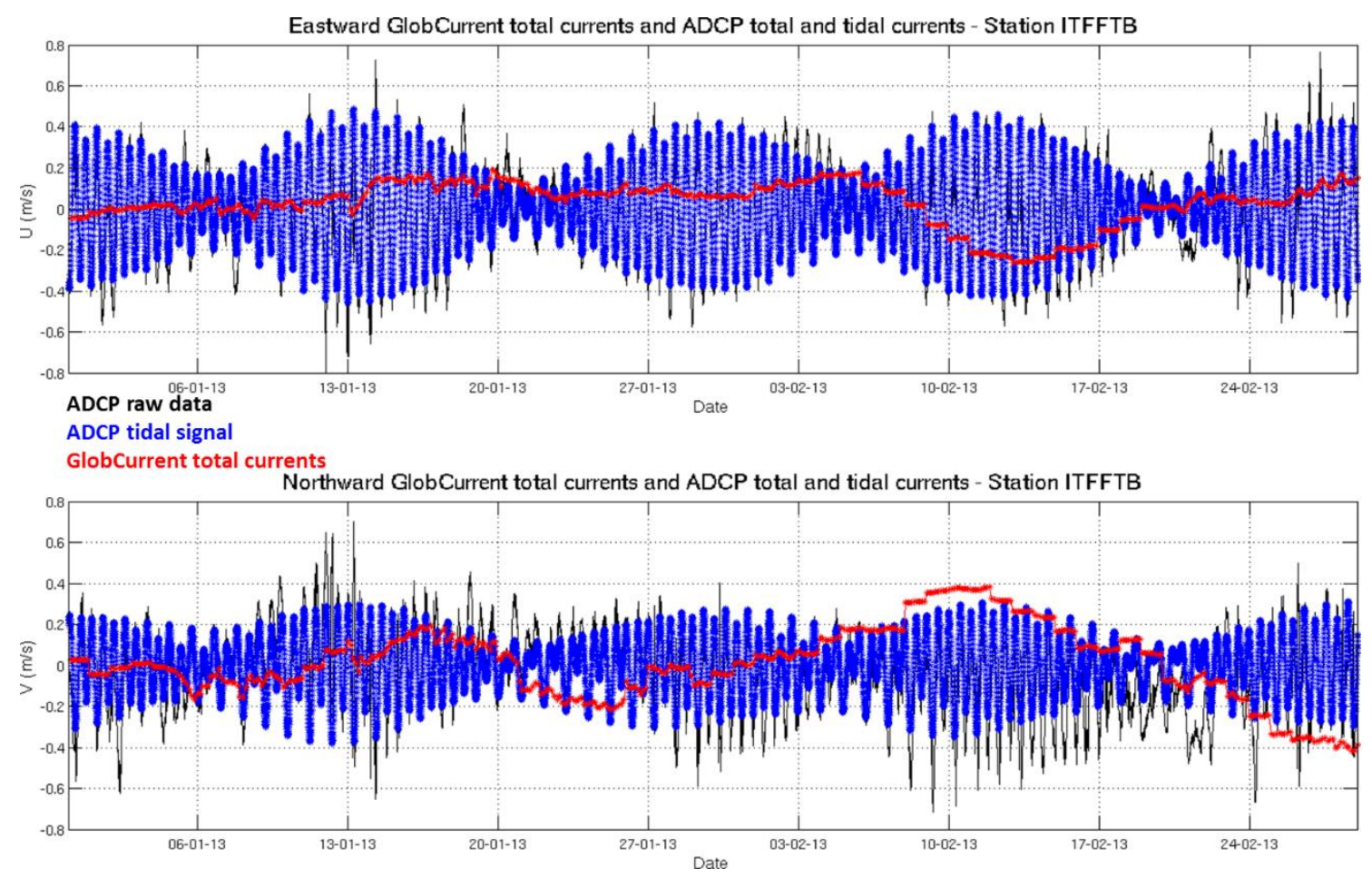

Figure 18: Extract of the time series of the eastward and northward currents at the ITFFTB ADCP station, for the raw data at 15-m depth (in black), the tidal signal extracted from these raw data by harmonic analysis (in blue) and the GlobCurrent total currents at 15-m depth extracted at the ADCP location (in red). Jan.-Feb. 2013. 


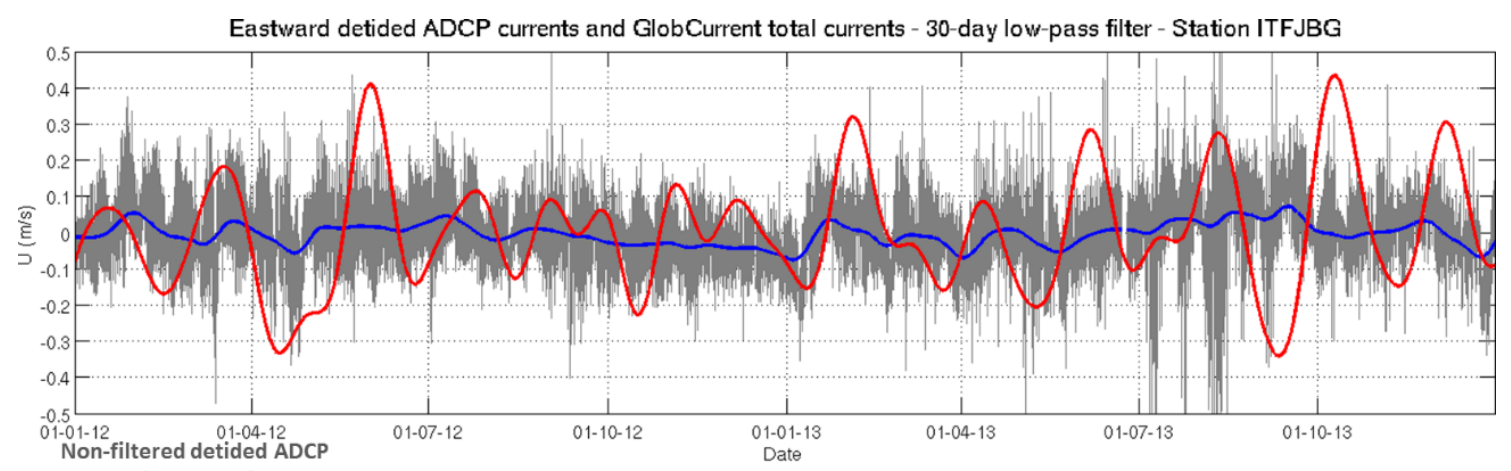

30-day filtered detided $A D C P$

30-day filtered GlobCurrent total currents

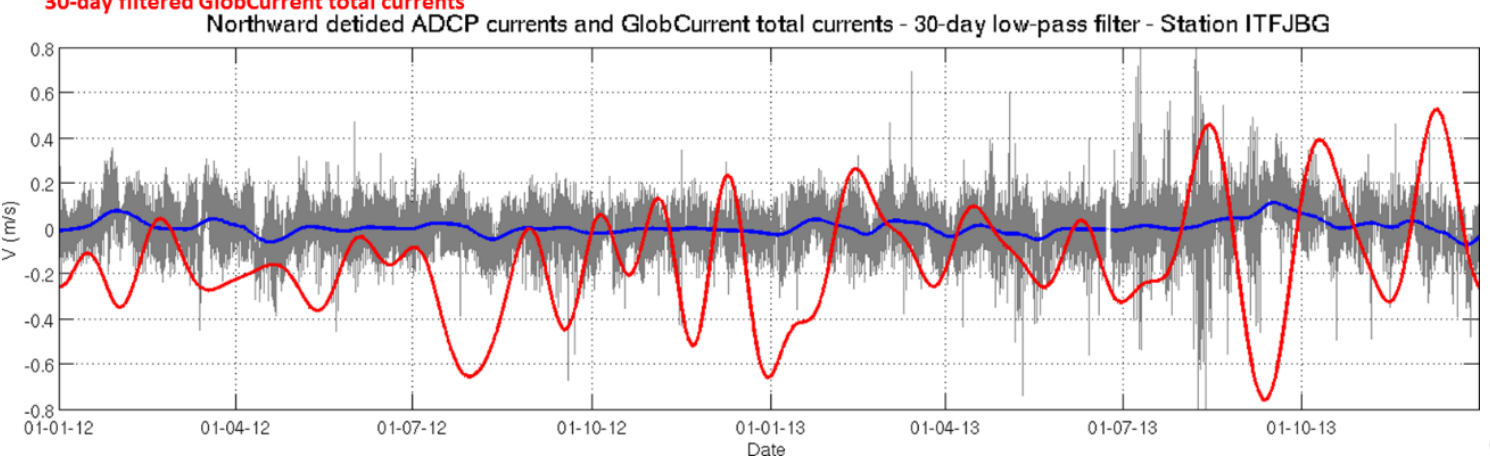

(a)

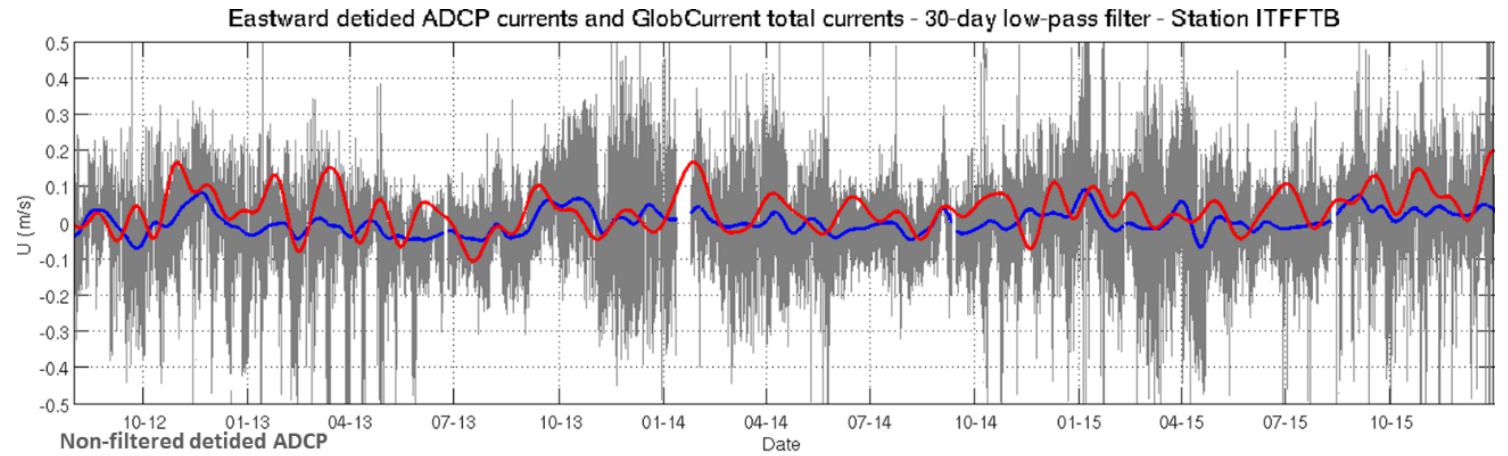

30-day

30-day filtered GlobCurrent total currents

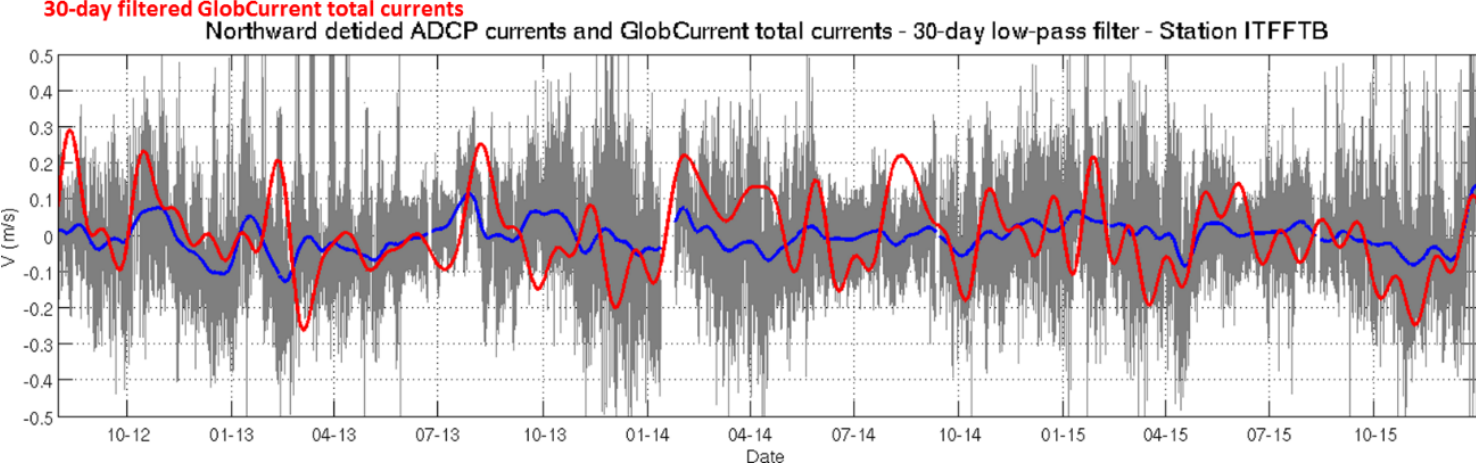

(b) 


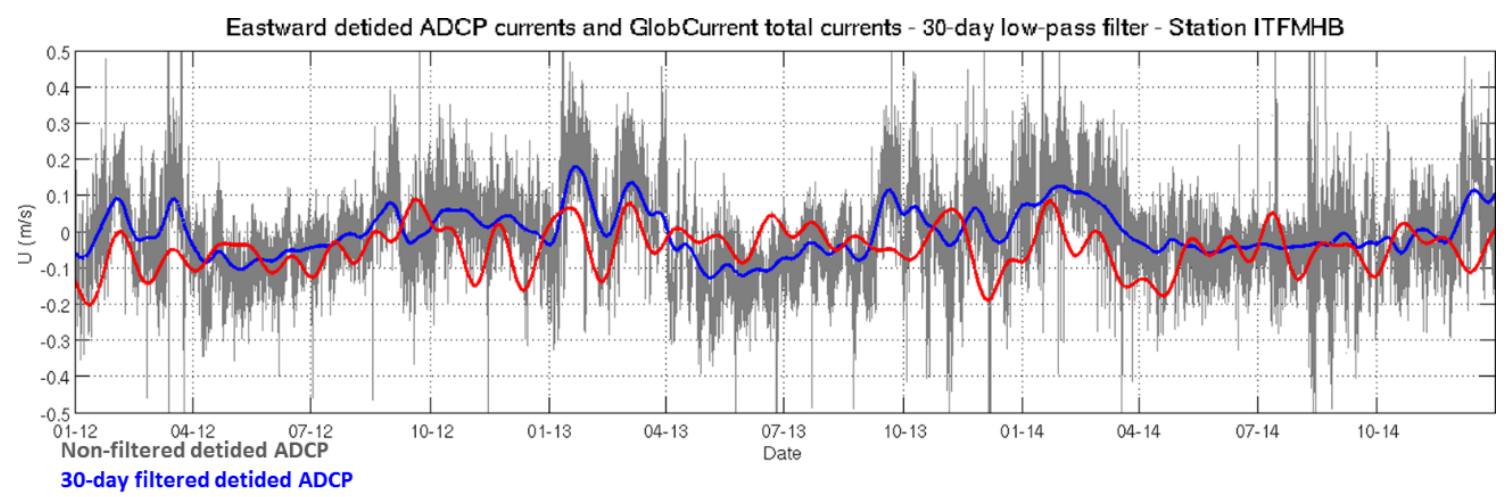

30-day filtered detided ADCP

30-day filtered GlobCurrent total currents

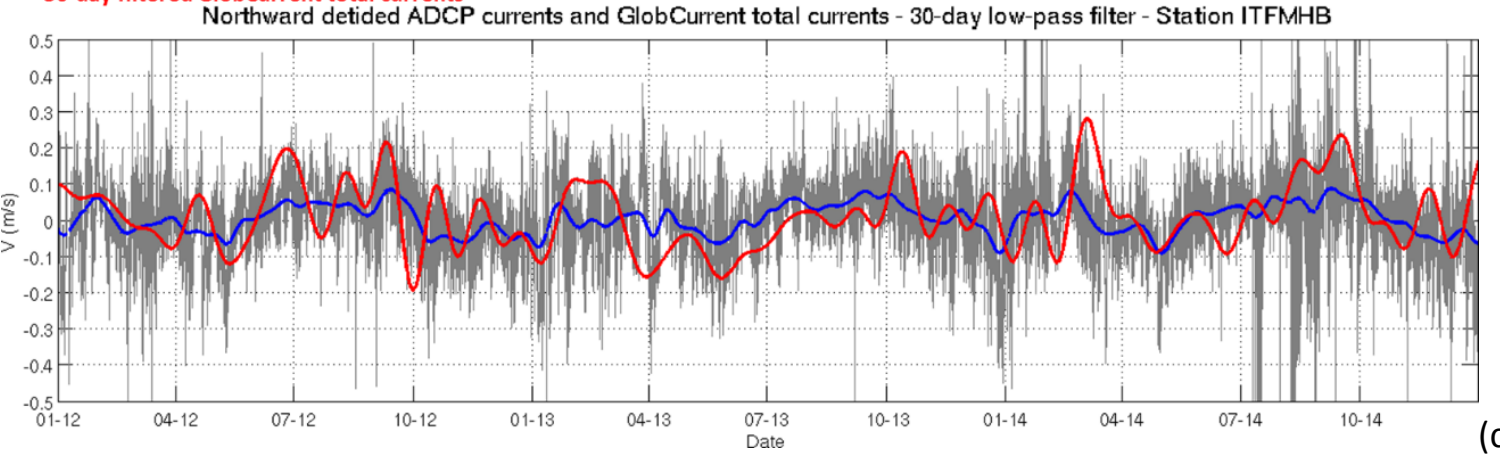

(c)

Figure 19 : Time series of the eastward and northward ADCP residual currents at 15-m depth (raw currents-

tidal currents), non-filtered data in gray, 30-day low-pass filtered data in blue, and 30-day low-pass filtered

GlobCurrent total currents at $15 \mathrm{~m}$ in red, at the three ADCP stations: ITFJBG (a), ITFFTB (b) and ITFMHB

(c). 


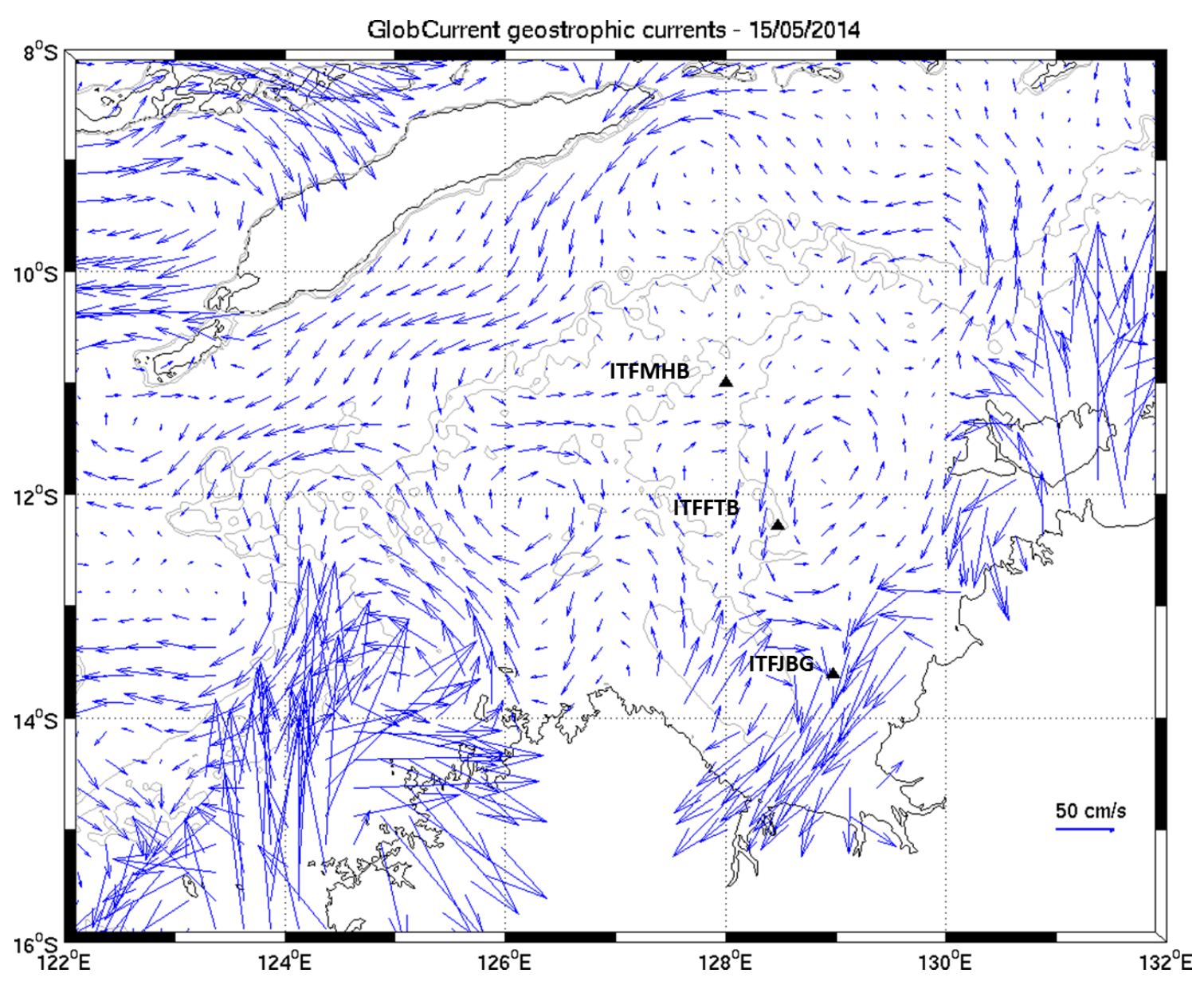

Figure 20: GlobCurrent geostrophic currents on the 15/05/2014 in the Joseph Bonaparte Gulf. The location of the three ADCP stations are shown with black triangles. The light gray lines show the 100m and 200m isobaths.

\section{Discussion and conclusions}

In this paper, we have analyzed the consistency of the GlobCurrent ocean surface current products with in situ data (ADCP and drifting buoys velocities) in two specific regions off Australia: the South-East, where the East Australian Current predominates, and the Joseph Bonaparte Gulf, where tides and wind-driven currents predominate.

The results obtained for the on-shelf portion of South-East region, using the ADCP stations of SYD100, SYD140 and NRSNSI, indicate clearly that the GlobCurrent ocean surface currents are not fitted for shelf applications, at least in this and probably other similar regions. These current fields strongly rely on the accuracy of the MDT, whose spatial resolution is not 
sufficient in the area, and on the satellite altimetry data coverage and quality, which both decrease near the coasts. The spatial resolution of the GlobCurrent products on the continental shelf is certainly too coarse to be able to represent the coastal processes, such as the upwelling which is known to occur in the region with the combination of encroachments of the EAC and southward winds (Roughan and Middleton, 2004). The coast of New South Wales and southern Queensland is also known to act as a wave-guide for coastal-trapped waves, which have moderately strong currents and a coastal sea level signal at scales that are smaller than the spatiotemporal scales of the GlobCurrent products, but are certainly seen by the ADCP instruments.

The offshore pseudo-drifter exercise gives a very good overview of the performance of the GlobCurrent products in the EAC region. It shows that the large and main structures of the ocean dynamics (EAC and eddies with diameters larger than $100 \mathrm{~km}$ ) are rather well located on the maps, with spatial extensions consistent with the structures that are described by the real drifters trajectories. The smaller structures may not be always well located because of the intertrack distance of the satellite altimetry missions used to map the geostrophic currents. Indeed, these small structures $(<100 \mathrm{~km})$ can occur in these inter-track intervals and never be sampled by the satellites. The Ekman current contribution in the GlobCurrent total currents product also clearly brings valuable information to the total surface current estimates. The pseudo-drifters advected by the GlobCurrent total current fields generally agree better with the real drifter trajectory than the pseudo-drifters advected by the GlobCurrent geostrophic current fields. However, the GlobCurrent products sometimes lack energy, probably because of the way they are constructed (optimal interpolation of satellite altimetry data and Ekman component derived from wind maps).

For the tidally-dominated North-West region, it is obviously important to take tides into consideration to obtain useful estimates of the total speed, so users will need to add tidal 
predictions to the GlobCurrent estimates of the lower-frequency velocity, otherwise there is an 'omission error' that can reach $0.5 \mathrm{~m} / \mathrm{s}$ or more. For the non-tidal component of the current velocity, we find that the GlobCurrent products do not provide useful estimates, showing large unrealistic features on the shelf. These features are presumably due to incomplete de-aliasing of tide and wind-driven sea level variability in the altimetry sea surface anomalies that are used to compute the geostrophic current maps. Indeed, the global models used to remove these signals from the altimetry sea surface heights probably lack resolution in this wide shelf region to provide accurate corrections. Also, the mean sea surface used to compute the altimetry sea level anomalies probably contains large errors in this shelf region. All those errors result in artificial features in the GlobCurrent geostrophic currents.

Therefore, the GlobCurrent products should be used very carefully in such wide-shelf regions, especially if the tides are large and the high-frequency variability is not well modelled by the global models used for de-aliasing altimetry data in order to estimate the low frequency variability from the sparse data produced by the present constellation of (nadir-sampling) altimeters.

More generally, the GlobCurrent products could benefit from current efforts in many ways. Much progress has been made in coastal altimetry processing for these last ten years, including coastal waveforms retracking techniques, coastal corrections processing strategies and high resolution regional tidal models. The new generation of satellite altimeters, such as Sentinel-3, measures the sea surface height in SAR mode, which brings higher along-track resolution. The geodetic or quasi-geodetic missions, such as Jason-1 and CryoSat-2, are also of great relevance to improve the mean sea surface and the mean dynamic topography close to the coasts. Work is also on-going to optimize the parameters of the optimal interpolation technique used to grid the altimetry data, with very promising results regarding the location, amplitude and lifespan of the ocean dynamics pattern with size ranging between 50 and $100 \mathrm{~km}$ 
(Ubelmann et al, 2015). All these new methods and datasets should improve the GlobCurrentstyle products in terms of geostrophic currents.

The quality of the Ekman current component in the GlobCurrent products could probably be increased by using higher spatiotemporal resolution wind fields.

Finally, it should be mentioned that global tidal atlases could be potentially used to complete the GlobCurrent suite of products. For example, the FES2014 (Carrère et al, 2015) and TPXO (Egbert and Erofeeva, 2002) global models are distributed not only with the tidal elevations but also with the tidal currents. Even if these tidal models are based on barotropic hydrodynamic assumptions, they would bring a first approximation of the main tidal signals in this kind of regions, or could be replaced with regional 3-D models if available.

\section{Acknowledgements}

This work was supported by the Data User Element program of the European Space Agency. The GlobCurrent data (version 3) were downloaded from the GlobCurrent portal on the 09/03/2017. The ADCP data are processed and provided by IMOS. They were downloaded from the IMOS portal on the 07/01/2017. The drifting buoys data were processed and provided by NOAA/AOML. They were downloaded from AOML service on the 12/04/2017.

\section{References}

Ardhuin, F., Y. Aksenov, A. Benetazzo, L. Bertino, P. Brandt, E. Caubet, B. Chapron, F. Collard, S. Cravatte, F. Dias, et al. (2017), Measuring currents, ice drift, and waves from space: the Sea Surface KInematics Multiscale monitoring (SKIM) concept, Ocean Sci. Discuss., https://doi.org/10.5194/os-2017-65, in review 
Bonjean, F., and G. S. E. Lagerloef, 2002. Diagnostic model and analysis of the surface currents in the tropical Pacific Ocean. J. Phys. Oceanogr., vol. 32, pg. 2938-2954.

Bowen, M. M., J. L. Wilkin, and W. J. Emery (2005), Variability and forcing of the East Australian Current, J. Geophys. Res., 110, C03019, doi: 10.1029/2004JC002533.

Carrère, L., Lyard, F., Cancet, M., Guillot, A., Picot, N., Dupuy, S. (2015), FES2014: A new global tidal model, presented at the Ocean Surface Topography Science Team meeting, Reston, USA.

Egbert G. D. and Erofeeva S. Y. (2002), Efficient inverse modeling of barotropic ocean tides. J. Atmos. Oceanic Technol., 19 (2), 183-204.

Griffin, D.A. and Middleton, J.H. (1991). Local and remote wind forcing of New South Wales inner shelf currents and sea level. J. Phys. Oceanogr., 21, 304-322.

Le Traon, P.Y. and G. Dibarboure, 2002 Velocity mapping capabilities of present and future altimeter missions: the role of high frequency signals. J. Atmos. Oceanic Technol., 19, 20772088.

Liu, Y., and R. H. Weisberg (2011), Evaluation of trajectory modeling in different dynamic regions using normalizedcumulative Lagrangian separation, J. Geophys. Res., 116, C09013, doi:10.1029/2010JC006837

Liu, Y., R. H. Weisberg, S. Vignudelli, and G. T. Mitchum (2014), Evaluation of altimetryderived surface current products using Lagrangian drifter trajectories in the eastern Gulf of Mexico, J. Geophys. Res. Oceans, 119, 2827-2842, doi:10.1002/2013JC009710.

Lumpkin, R., Semyon A. Grodsky, Luca Centurioni, Marie-Helene Rio, James A. Carton, and Dongkyu Lee (2013), Removing Spurious Low-Frequency Variability in Drifter Velocities, J. Atmos. Oceanic Technol., 30, 353-360, doi: https://doi.org/10.1175/JTECH-D-12-00139.1 
Martin, A. C. H., and C. Gommenginger (2017), Towards wide-swath high-resolution mapping of total ocean surface current vectors from space: Airborne proof-of-concept and validation, Remote Sensing of Environment, Volume 197, August 2017, Pages 58-71, doi: 10.1016/j.rse.2017.05.020

Mata, M. M., S. E. Wijffels, J. A. Church, and M. Tomczak (2006), Eddy shedding and energy conversions in the East Australian Current, J. Geophys. Res., 111, C09034, doi:10.1029/2006JC003592.

Ridgway, K. and Hill, K. (2009), The East Australian Current. In A Marine Climate Change Impacts and Adaptation Report Card for Australia 2009 (Eds. E.S. Poloczanska, A.J. Hobday and A.J. Richardson), NCCARF Publication 05/09, ISBN 978-1-921609-03-9

Rio, M-H, S. Mulet, and N. Picot (2013): New global Mean Dynamic Topography from a GOCE geoid model, altimeter measurements and oceanographic in-situ data. Proceedings of the ESA Living Planet Symposium, Edinburg, September 2013.

Rio, M.-H., S. Mulet, and N. Picot (2014), Beyond GOCE for the ocean circulation estimate: Synergetic use of altimetry, gravimetry, and in situ data provides new insight into geostrophic and Ekman currents, Geophys. Res. Lett., 41, doi:10.1002/2014GL061773

Rio, M.-H. (2015), Globcurrent Product Data Handbook: the combined geostrophy + Ekman currents

(ftp://ftp.ifremer.fr/ifremer/cersat/documentation/gridded/globcurrent/GlobCurrent_D280_Product_Handbook_L4_combined_mhr.pdf)

Roughan, M., and J. H. Middleton (2004), On the East Australian Current: Variability, encroachment, and upwelling, J. Geophys. Res., 109, C07003, doi:10.1029/2003JC001833 
Sudre, J., Maes, C., and V. Garçon (2013), On the global estimates of geostrophic and Ekman surface currents, Limnology and Oceanography: Fluids and Environments, 3, pp 1-20, DOI $10.1215 / 21573689-2071927$

Suthers, I. M., J. W. Young, M. E. Baird, M. Roughan, J. D. Everett, G. B. Brassington, M. Byrne, S. A. Condie, J. R. Hartog, C. S. Hassler, et al, (2011), Editorial: The strengthening East Australian Current, its eddies and biological effects - an introduction and overview, Deep-Sea Research II, 58, pp: 538-546. doi:10.1016/j.dsr2.2010.09.029

Ubelmann C, Klein P, Fu L L (2015), Dynamic interpolation of sea surface height and potential applications for future high-resolution altimetry mapping. $\mathrm{J}$ Atmos Ocean Technol. doi:10.1175/jtech-d-14-00152.1 